IZA DP No. 1906

\title{
Education Policy and Equality of Opportunity
}

\section{Gabriela Schütz}

Heinrich W. Ursprung

Ludger Woessmann

December 2005 


\title{
Education Policy and Equality of Opportunity
}

\author{
Gabriela Schütz \\ Ifo Institute, University of Munich \\ Heinrich W. Ursprung \\ University of Konstanz \\ and CESifo \\ Ludger Woessmann \\ Ifo Institute, University of Munich, \\ CESifo and IZA Bonn

\section{Discussion Paper No. 1906 \\ December 2005}

\author{
IZA \\ P.O. Box 7240 \\ 53072 Bonn \\ Germany \\ Phone: +49-228-3894-0 \\ Fax: +49-228-3894-180 \\ Email: iza@iza.org
}

\begin{abstract}
Any opinions expressed here are those of the author(s) and not those of the institute. Research disseminated by IZA may include views on policy, but the institute itself takes no institutional policy positions.

The Institute for the Study of Labor (IZA) in Bonn is a local and virtual international research center and a place of communication between science, politics and business. IZA is an independent nonprofit company supported by Deutsche Post World Net. The center is associated with the University of Bonn and offers a stimulating research environment through its research networks, research support, and visitors and doctoral programs. IZA engages in (i) original and internationally competitive research in all fields of labor economics, (ii) development of policy concepts, and (iii) dissemination of research results and concepts to the interested public.
\end{abstract}

IZA Discussion Papers often represent preliminary work and are circulated to encourage discussion. Citation of such a paper should account for its provisional character. A revised version may be available directly from the author. 
IZA Discussion Paper No. 1906

December 2005

\section{ABSTRACT}

\section{Education Policy and Equality of Opportunity*}

We provide a measure of equality of educational opportunity in 54 countries, estimated as the effect of family background on student performance in two international TIMSS tests. We then show how organizational features of the education system affect equality of educational opportunity. Our model predicts that late tracking and a long pre-school cycle are beneficial for equality, while pre-school enrollment is detrimental at low levels of enrollment and beneficial at higher levels. Using cross-country variations in education policies and their interaction with family background at the student level, we provide empirical evidence supportive of these predictions.

JEL Classification: $\quad$ I21, J62, H52

Keywords: equality of opportunity, educational production, family background, student performance, tracking, pre-school, efficiency-equity tradeoff

Corresponding author:

Ludger Woessmann

ifo Institute for Economic Research

University of Munich

Poschingerstr. 5

81679 Munich

Germany

Email:woessmann@ifo.de

\footnotetext{
* For helpful comments and discussion, we would like to thank Steve Machin, Winfried Pohlmeier and Joachim Winter, as well as participants at the joint SOLE/EALE World Conference on Labor Economics in San Francisco.
} 


\section{Introduction}

Equality in educational outcomes is a crucial determinant of the extent of equality of opportunity and intergenerational mobility achieved by societies. Nickell (2004), for example, shows that a large part of the existing cross-country variation in earnings inequality can be attributed to cross-country variation in skill dispersion. It is, therefore, of prime policy interest to understand the effects of education policies such as ability tracking, pre-school education, length of the school day and educational spending on the educational success of children from various family backgrounds. The direction of these effects is, however, by no means straightforward from a theory point of view, and empirical evidence is limited. The lack of empirical evidence derives from the fact that variation in the organization of education systems is largely lacking within countries, and where it is not, it is unlikely to be exogenous to students' performance and family backgrounds.

This state of affairs is the starting point of our paper which makes three contributions. First, it provides a comparable measure for 54 countries of how strongly children's educational performance is related to their family background (Section 2). We interpret this measure as a proxy for the extent of inequality of opportunity. Second, the paper develops a theoretical model that traces the effect of different education policies on the equality of opportunity (Section 3). Third, we present empirical evidence, using cross-country variations in education policies and their interaction with family background at the individual student level to identify the impact of education policies on equality of opportunity (Section 4).

The database used combines two related extensive international student achievement tests, the Third International Mathematics and Science Study (TIMSS) and its replication for a partly different set of countries (TIMSS-Repeat) (Section 2.1). These datasets provide information on students' educational performance, their family background and relevant control variables for individual students in each participating country. As our main indicator of family background, we use the number of books in the students' home. As suggested in the sociological literature, books at home provide a powerful proxy for the educational, social and economic background of the students' families. Moreover, previous research on the same and other datasets suggests that in most countries, books at home are the single most important predictor of student performance, even surpassing parental education (Wößmann 2003, 2004; Fuchs and Wößmann 2004). Furthermore, data coverage on this indicator is superior to parental education, and we argue that it is more readily comparable across countries. 
This database allows us to estimate an index of equality of educational opportunity in 54 countries (Section 2.2). More precisely, the index measures the inequality of educational outcomes for children from different family backgrounds. Given the strong relationship between education and economic outcomes, our measure can thus also serve as an index of the inequality of opportunity later in life for children from different family backgrounds. To our knowledge, no previous evidence on the inequality of opportunity across countries has been available on a comparable scale. In estimating our index at the micro level, we make sure that it is not affected by cross-country differences in the immigrant population, but only reflects performance differences associated with socio-economic background.

Our results show that equality of opportunity as measured by our index varies considerably across countries (Section 2.3). Among OECD countries, the impact of our family-background measure on student performance is largest in England, Scotland, Hungary and Germany and lowest in France, Canada, Portugal and Flemish Belgium. The family-background effect in the former countries is on average 2.7 times as large as in the latter countries. The United States falls in the top quarter of the most unequal OECD countries.

To understand the substantial cross-country variation in the extent of equality of educational opportunity, we develop a model to explain how key organizational features of school systems affect the extent to which equality of educational opportunity is achieved. These features include the duration of and enrollment in pre-school education (Section 3.1) and the timing of the change from comprehensiveness to ability tracking in the school system (Section 3.2). Numerical solution of the model suggests that late tracking and a long preschool cycle are beneficial for equality of opportunity, while pre-school enrollment has a detrimental influence at low levels of enrollment and a beneficial influence at higher levels (Section 3.3).

Combining the observed variation in the index of educational inequality with country-level data on features of the education systems, we can test the predictions of our model empirically. Our preferred empirical identification strategy is to estimate how the different country-level features of the school systems interact with the family-background measure at the student level in determining student performance, while at the same time controlling for unobserved country heterogeneity by country fixed effects (Section 4.1).

The empirical results strongly support our theoretical model. We find that the familybackground effect is larger (i.e. equality of opportunity is lower), the earlier a country tracks its students into different school types by ability (Section 4.2). Also, the family-background 
effect is larger in countries with shorter pre-school education. With respect to pre-school enrollment, we find an inverted U-shaped relationship, with educational inequality increasing up to an enrollment of roughly 60 percent and decreasing thereafter. These results prove robust to more extensive model specifications, in which we do not find a statistically significant difference in the equality of opportunity by school starting age or between half-day and whole-day school systems. Neither does the observed equality of opportunity differ with average educational spending, nor with the country's level of economic development. At least in the OECD sample, there is also no statistically significant relationship between equality of opportunity and a country's mean test score. Finally, the family-background effect is larger in countries with a larger share of private funding, but at the same time, it is smaller in countries with a larger share of private provision.

Our theoretical and empirical results thus show how school systems can accelerate intergenerational mobility. The results suggest that education policies such as comprehensive school systems and extensive early-childhood education can increase the equality of educational opportunity for children from different family backgrounds. ${ }^{1}$ The empirical evidence on the other hand also suggests that extending the school day into the afternoon, bringing forward the age at which compulsory education begins or increasing educational spending do not appear to have a significant effect on the equality of educational opportunity. There also does not appear to exist an efficiency-equity tradeoff in education in the sense that more equal systems would systematically affect the mean performance of their students, at least not among OECD countries. Relying on private spending to finance education varies positively with increased inequality of educational opportunity, relying on private production of schooling on the other hand varies positively with equality of educational opportunity.

\section{Estimating Equality of Opportunity across Countries}

\subsection{Data}

\subsubsection{The Two TIMSS International Student Achievement Studies}

To derive estimates of the equality of educational opportunity, we employ student-level micro data from two extensive international student achievement tests. The first test is the Third

\footnotetext{
${ }^{1}$ For selected previous analyses of ability tracking, cf. Betts and Skolnick (2000), Figlio and Page (2002), Epple et al. (2002), Galindo-Rueda and Vignoles (2004), Meghir and Palme (2005) and Hanushek and Wößmann (2005). For recent evidence on the effects of early-childhood education, cf. Garces et al. (2002), Magnuson et al. (2004) and Schweinhart et al. (2005); Barnett (1992) and Currie (2001) provide surveys of previous analyses.
} 
International Mathematics and Science Study (TIMSS), conducted in 1995 (data released in 1997) by the International Association for the Evaluation of Educational Achievement (IEA), an independent cooperation of national, partly governmental, research agencies. The second test is the TIMSS-Repeat study, conducted in 1999 (data released in 2001) also by the IEA as a replication of the first study. All participating countries received the same test items, so that the ensuing measures of educational performance in math and science are directly comparable across countries. ${ }^{2}$ Furthermore, both tests draw random samples of schools to provide representative samples of students in each participating country. ${ }^{3}$

The target population of TIMSS-Repeat was the upper of the two adjacent grades with the largest share of 13-year-olds (usually eighth grade). While the TIMSS-95 study also targeted additional grade levels, we restrict our TIMSS-95 data to the eighth-grade students to ensure comparability. For our analyses, TIMSS-95 yielded internationally comparable data for representative samples of students in 40 countries, and TIMSS-Repeat for 38 countries. ${ }^{4}$ Since the sample of participating countries differed considerably between the two tests, the pooled TIMSS-95/TIMSS-Repeat database contains data on more than 300,000 students from 54 different countries, which is the biggest sample of participating countries in comparable international tests to date (see Table 1 for a list of the countries).

Both studies had basically the same design of a curriculum-valid test. Given that twothirds of the test items of TIMSS-95 had been released to the public after the study, these items had to be replaced in TIMSS-Repeat by substitute items with similar content, format and level of difficulty. Because of the similarity of the test designs, it is possible to splice the eighth-grade data of the two TIMSS tests together. We do this by singling out the test scores of those 24 countries that participated in both studies and standardizing all scores according to the mean and the standard deviation of this sub-sample. We then standardize the test scores to have a standard deviation of 100 across all countries in the pooled dataset.

In this paper, we use the mean of the math and the science test scores of each student as our measure of educational performance, pooling the two TIMSS tests for those countries that

\footnotetext{
2 The development of the test contents was a cooperative process involving national research coordinators from all participating countries, and all participating countries endorsed the curriculum framework. Both studies also performed a test-curriculum matching analysis that restricted the analysis to items definitely covered in each country's curriculum, which made little difference for the overall achievement patterns.

3 Beaton et al. (1996), Gonzalez and Smith (1997) and Martin and Kelly (1996, 1997) provide detailed information on the TIMSS-95 database. For more information on the TIMSS-Repeat database, see Mullis et al. (2000), Martin et al. (2000) and Gonzalez and Miles (2001).

${ }^{4}$ England and Scotland, as well as the Flemish and the French school system in Belgium, count as individual countries here as they have separate school systems that participated separately in the tests.
} 
participated in both studies. Table 1 reports each country's mean performance and standard deviation on this variable.

In separate background questionnaires, students were asked to provide information on various features of their family background. These features include the number of books in their home (see next sub-section for details), whether they themselves, their mother and their father were born in the country, their family status (living together with both parents or not), their gender and age. Table 2 contains descriptive statistics on these variables for the international dataset. 5

\subsubsection{The Family-Background Proxy}

The proxy for the family background of students that we use in our study is the number of books in the students' home. "Books at home” is a measure of family background proposed and frequently used in sociological research. A large number of books can be interpreted as an indicator for a family environment that highly esteems education and academic success and that will promote children's academic effort (cf. Beaton et al. 1996; Mullis et al. 2000). Furthermore, the number of books at home proxies for the social background of the parents. It also proxies for their economic background, since books are goods that have to be paid for. Thus, the variable "books at home” provides a proxy for the educational, social and economic background of the students' families.

In both TIMSS tests, the number of books at home was reported by the students themselves in the student background questionnaire according to the following question: “About how many books are there in your home? (Do not count magazines, newspapers, or your school books.)” The following five answer categories were given: 1 - "none or very few (0-10 books)"; 2 - “enough to fill one shelf (11-25 books)"; 3 - “enough to fill one bookcase (26-100 books)"; 4 - “enough to fill two bookcases (101-200 books)”; 5 - “enough to fill three or more bookcases (more than 200 books)”. Table 1 reports the frequency with which each category was answered in each country.

An obvious alternative to the books-at-home proxy would be to use parental education as a proxy for family background. ${ }^{6}$ However, we view the books-at-home proxy as preferable for

\footnotetext{
5 The small number of observations with missing data on these variables was dropped from the estimations in this paper.

6 Other family-background proxies used in sociological research include parental occupation and indices of socio-economic status, usually also based on occupational status. For example, one widely used index is some form of the International Socio-Economic Index (ISEI), which derives from a classification of occupational status by Ganzeboom et al. (1992). Their mapping from occupational to socio-economic status is based on only
} 
several reasons. First, previous results based on the TIMSS as well as on the PISA 2000 dataset have shown that, on average, books at home are the single most important predictor of student performance, considerably stronger than parental education (see Wößmann 2003, 2004 for TIMSS; Fuchs and Wößmann 2004 for PISA). ${ }^{7}$ Second, even when the parents’ level of education is reported using international standards such as the International Standard Classification of Education (ISCED), specific educational tracks differ considerably across countries. Thus, a given level of education does not imply the same knowledge in all countries, so that the cross-country comparability may be limited. In terms of mere units of measurement, the cross-country comparability of counting books at home is much more straightforward. Third, there is a TIMSS-specific data problem, since parental education is measured slightly differently in TIMSS-95 and TIMSS-Repeat (due to an interim adjustment of the ISCED classification), while the scaling of the books at home variable remained exactly the same. Finally, there is also a second, more general data problem, insofar as substantially more observations are missing for the parental education variable than for the books-at-home variable. E.g., about one third of the observations on parental education in the Western European countries are missing in the TIMSS dataset, while the average fraction of missing observations of the books-at-home variable in the same countries is less than three percent (cf. Wößmann 2004).

Despite these relative advantages of the books-at-home proxy, it is still only a proxy for family background and has, therefore, its limitations. In particular, although it is reasonable to assume that the socio-economic position of a family is positively correlated with the number of books it owns, it is possible that this correlation varies across countries with different cultures' differing appreciation of books. The extent to which this is the case, and the extent to which this might bias the results reported in this study, is a priori unclear. We do not know of any study that has tried to validate the cross-cultural comparability of the number of books at home as a family-background proxy. ${ }^{8}$

16 countries, however. The TIMSS studies do not provide data on parental occupation, and the cross-country comparability of occupational status may be more limited than that of books at home.

7 Results on the PISA data, which contain information on the work status and occupation of parents, also reveal that books at home are on average a stronger predictor of student performance than parental work status and occupation (Fuchs and Wößmann 2004). The PISA data also show that there are more missing observations on the occupation variable than on the books-at-home variable.

8 When experimenting with the parental-education measure as an alternative measure for socio-economic background, we found that the general pattern of results does look quite similar, although there are sizable differences for a few countries. 
Taking these caveats into account, we suggest the following procedure to test for the crosscountry validity of the books-at-home variable. We are aware of one international student achievement test which provides data on both books at home and household income (which unfortunately has much fewer participating countries than the pooled TIMSS tests). This is the Progress in International Reading Literacy Study (PIRLS), also conducted by the IEA, that tested fourth-grade students in 2001 (data released in 2003). PIRLS contained a home background questionnaire, completed by the parents of tested students, which asked both about the before-tax annual household income (in six bracketed categories) and about the number of books in their home (in five categories, in exactly the same way as in TIMSS). In a sense, household income may be viewed as the "ideal” measure of family background, at least from an economic perspective. Given this dataset containing both income and books information, we can test whether the correlation between household income and books at home varies across countries. Unfortunately, there are only six OECD countries for which PIRLS provides income data in a comparable way (England, Germany, the Netherlands, Norway, the Slovak Republic and Sweden).

When we regress the categorically measured income variable on the books-at-home categorical variable, country dummies and interactions between books at home and the country dummies, none of the interactions is statistically or quantitatively significant. This is despite the fact that the coefficient on books at home is statistically and quantitatively highly significant: Given that the six-country sample contains 20,343 students, the effect is very precisely estimated, at 0.528 with a standard deviation of only 0.009 (t-statistic: 61.0$)$. While this means that the 95-percent confidence interval ranges only from 0.511 to 0.545 , still none of the country interactions is statistically significant, with their size varying only from -0.048 to 0.045 . That is, the association between household income and books at home does not vary significantly between the countries. We view this as strong evidence in favor of the validity of cross-country comparisons where the books-at-home variable proxies for family background.

\subsection{The Empirical Specification}

To estimate the extent of equality of educational opportunity achieved in country $j$, we regress the test performance of individual students on our proxy for family background, i.e. the number of books at home, and a set of control variables, separately for each country $j$ :

$$
\begin{aligned}
T_{i s j} & =\alpha_{j}+\beta_{j} B_{i s j}+\gamma_{1 j} A_{i s j}+\gamma_{2 j} G_{i s j}+\gamma_{3 j} F_{i s j}+\gamma_{4 j} S_{i s j} \\
& +\gamma_{5 j} I_{i s j}^{i}+\gamma_{6 j} I_{i s j}^{m}+\gamma_{7 j} I_{i s j}^{f}+\gamma_{8 j}\left(I_{i s j}^{i} B_{i s j}\right)+\gamma_{9 j}\left(I_{i s j}^{m} B_{i s j}\right)+\gamma_{10 j}\left(I_{i s j}^{f} B_{i s j}\right)+\varepsilon_{i s j},
\end{aligned}
$$


where $T_{i s j}$ is test score of student $i$ in school $s$ in country $j$ and $B_{i s j}$ is our measure of books in the individual student's home. The set of control variables includes: a constant $\alpha_{j}$, student age $A_{i s j}$, student gender $G_{i s j}$, a dummy for family composition $F_{i s j}$ indicating whether the student lives together with both parents and, for the countries participating in both TIMSS studies, a study dummy $S_{i s j}$. Furthermore, the regressions control for three immigration status dummies, indicating whether the student $\left(I_{i s j}^{i}\right)$, the mother $\left(I_{i s j}^{m}\right)$ and the father $\left(I_{i s j}^{f}\right)$ were born in the country, respectively. Finally, the regressions control for interaction terms between these three immigration dummies and books at home. $\varepsilon_{i s j}$ is the error term.

In the following, we first discuss the functional form of the relation between test scores and books at home, which will be followed by a discussion of the inclusion of control variables in general and the immigration controls in particular, as well as of the specific structure of the error term.

We enter the books-at-home variable $B_{i s j}$ as a categorical variable ranging from 1 to 5 according to the five answer categories reported in Section 2.1.2 above. This approach is valid under the assumption that the performance differences of students between each of these categories are roughly the same. Specification tests suggest that this is a valid assumption, as the suggested functional form represents the data particularly well. That is, we initially estimated a form of equation (1) for the pooled sample of all countries (controlling for country fixed effects) in which we entered four dummies to represent the five available books-at-home categories individually (leaving the lowest one out as the residual category). This estimation does not place any restrictions on the functional form, as it uses all information available and allows the effect of books to vary in any possible way. The estimated coefficients on the four dummies showed a highly linear pattern. That is, when forcing the four steps to have equal length by applying the mean of the implied steps between the five categories (which was equal to 17.7) to each step, which implies the four linear steps of 17.7, 35.5, 53.2 and 71.0, these implied linear steps are very close to the actual estimates on the four dummies of 14.4, 38.4, 58.6 and 71.0. They all either fall within the 99\% confidence interval of the four directly estimated individual dummies or are very close to the bounds of these intervals. ${ }^{9}$ Thus, the linear functional form taking on values from 1 to 5 along the lines of the five answer categories reproduces the data considerably well.

\footnotetext{
9 The two deviations where the implied steps do not fall within the confidence intervals are that the first implied step of 17.7 is slightly above the upper bound of 17.1 of the $99 \%$ confidence interval of the direct
} 
The official TIMSS publications report simple (bivariate) comparisons of the average performance of students falling into different categories on a specific family-background variable (cf. Beaton et al. 1996; Mullis et al. 2000). However, such bivariate comparisons can easily be confounded by other basic characteristics of the students, such as age, gender, family composition and immigration status. Thus, our regressions include controls for these potentially confounding factors, thereby holding these factors constant when comparing the performance of students along the books-at-home dimension.

One particular criticism often raised against international comparisons of measures of dispersion in student achievements and the bivariate estimates of family-background effects (FBEs) is that countries have different immigrant populations. There are two reasons why immigrant populations may cause a bias in these bivariate estimates. First, if immigration status and family background (as proxied by books at home in our study) are correlated, international differences in estimated FBEs are biased when ignoring the immigration status. Second, the FBEs may be heterogeneous between native and immigrated families, which may introduce an additional bias to the cross-country pattern of estimated FBEs. Since we do not want our estimator of the strength of the influence of family background on student performance to be affected by the proportion of immigrant students in the respective countries, we calculate the FBEs net of immigration status. That is, we control for these potentially biasing effects already in the micro construction of our FBE measure. The three dummies for the immigration status of students, their mothers and their fathers ensure that the first possible cause for a bias does not affect our FBEs. The interaction terms between the three immigration dummies and our family-background measure ensure that the second possible case does bias our FBEs. Thus, our estimated FBEs represent only the familybackground influence of the native students in each country, which seems to be the best way to provide cross-country comparability despite cross-country differences in the immigrant population. ${ }^{10}$

Under the assumption that any factors which are not controlled for by the included explanatory variables, and which therefore enter the error term, are not systematically related to the number of books in the students' home, least-squares estimation of equation (1) yields

estimate on the first dummy, and that the third implied step of 53.2 is slightly below the lower bound of 55.3 of the $99 \%$ confidence interval of the direct estimate on the third dummy.

10 One way in which the size of the immigrant population could still affect our FBEs is if the size of the FBE among native students is affected, for example, by how many immigrants are in their specific class. 
an estimate of the influence of family background (as proxied by books at home) on student performance.

In estimating the error term $\varepsilon_{i s j}$ of equation (1), it has to be recognized that the performance of students within the same school may not be independent from one another (cf. Moulton 1986 for this problem of hierarchical data structure). Furthermore, the TIMSS sampling procedure had a two-stage clustered sampling design within each country (cf. Martin and Kelly 1996; Martin et al. 2000). At the first stage, schools were sampled, and at the second stage classrooms were sampled within these schools. Thus, the primary sampling unit (PSU) in TIMSS was the school. This suggests that the independence assumption usually made with respect to individual observations in standard econometric methods should be relaxed in favor of the assumption that only the variation between schools (PSUs) provides independent variation. This is implemented by the clustering-robust linear regression (CRLR) method, which allows any given amount of correlation of the error terms within PSUs and requires only that observations be independent across PSUs (cf. White 1984; Deaton 1997).

Since TIMSS used a stratified sampling design within each country, sampling probabilities vary for different students (Martin and Kelly 1996; Martin et al. 2000). We obtain nationally representative coefficient estimates by employing weighted least squares (WLS) regressions, using the sampling probabilities as weights. WLS estimation guarantees that the proportional contribution to the parameter estimates of each stratum in the sample is the same as if a complete census had been obtained (cf. DuMouchel and Duncan 1983; Wooldridge 2001).

\subsection{Results on the Family-Background Effects (FBEs)}

Our estimates of the family-background effect (FBE) in the 54 countries, estimated as $\beta_{j}$ in equation (1), are reported in Table 3. The results suggest that in all countries student performance is influenced in a statistically significant way by our family-background variable. ${ }^{11}$ The size of the estimated FBEs indicates how much students' test scores differ on average between the five categories of the variable "books at home" reported in Section 2.1.2. Since the performance of students was measured by standardized test scores with an international standard deviation of 100 , the coefficients can be interpreted as percentages of

\footnotetext{
11 The sole exception is Kuwait, whose estimate is not significantly different from zero at conventional levels of statistical significance, but only at 14 percent. The estimate in Colombia is statistically significant at the 5 percent level, while the estimates in all other countries reach statistical significance at the 1 percent level.
} 
an international standard deviation by which test achievement increases when raising the number of books at home by one category. ${ }^{12}$

In interpreting the estimated FBEs, first recall that initial evidence showed that each move from one books-at-home category to the next can be regarded as roughly equivalent in terms of its effect on test scores. The FBEs reported in Table 3 show by how much one of these steps changes the test scores in each country. Consider as an example the estimated FBE for the United States of 23.1. A 1-point difference in the family-background proxy - e.g., the difference in social background of US students that is equivalent to the difference between having one bookcase and two bookcases of books at home - goes hand in hand with a difference of 23.1 percent of an international standard deviation in test scores.

With an FBE of 23.1, the United States falls in the top quarter of the most unequal countries - both in the overall sample and in the OECD sub-sample. As the results of Table 3 show, England (28.8), Taiwan (27.9), Scotland (27.0), Hungary (25.8) and Germany (25.6) are the five countries with the largest estimated FBE in our sample of 54 countries. That is, they provide their students with the least equality of educational opportunity. On average, the impact of family background on student performance in these five countries is more than four times as large as in the countries with the smallest performance difference for students from different family backgrounds, Kuwait (2.5), Indonesia (4.8), Tunisia (6.3), Morocco (6.8) and Colombia (7.6). Their particularly low FBEs may be partly due to the fact that the average performance level of these countries is relatively low, so that the performance of all students is condensed at a rather low level. When looking at the more homogeneous sample of OECD countries, the countries that provide the largest extent of equality of educational opportunity to students from different family background are France (8.3), Canada (9.8), Portugal (10.4) and the Flemish school system in Belgium (11.0).

In sum, the estimated FBEs presented in Table 3 constitute a cross-country index of the inequality of educational opportunity that the different school systems achieve for students from different family backgrounds, where a high FBE value is associated with low equality of educational opportunity. The results show that there is substantial variation across countries in the extent to which equality of educational opportunity is achieved.

\footnotetext{
12 As France and Japan did not collect information on the immigration status of the parents, and France also not for the student, their estimated FBEs do not control for these variables.
} 


\section{School Systems and Equality of Opportunity: A Theoretical Model}

Given the cross-country variation in equality of educational opportunity revealed in the previous section, we analyze in the remaining two sections how this variation relates to features of the different school systems. To this end, we first develop a theoretical model of how key features of school systems affect equality of opportunity. In the next section, we then test the predictions of the model empirically.

\subsection{Pre-School Enrollment and Duration}

To shed some light on the complex relationship between the adopted school system and the effect of family background on educational achievement (the FBE), we focus on the main features that characterize school systems: the number of years children attend pre-school, the fraction of children attending pre-school and the age at which students are tracked into different schools according to ability. Since we attempt to identify the determinants of the FBE, we assume only one kind of heterogeneity, namely the students' family background that encompasses in particular family income, the parents' education and the parents' appreciation of formal education.

We assume that family background can be expressed by a real-numbered indicator $f$ that is uniformly distributed over the support $\left[f_{0}, f_{1}\right]$. The empirical literature on pre-school enrollment demonstrates that enrollment varies positively with family income and the parents' education, the reason being that formal day care centers may be more expensive than the informal alternatives and that well-educated parents value the human capital (cognitive skills and non-cognitive behavioral patterns) acquired in formal pre-school settings more than less educated parents (see, for example, the brief literature survey in Chiswick and DebBurman 2004). We do not explicitly model the parents' straightforward pre-school enrollment decision but focus on the special learning environment of formal pre-schools that is characterized by marked peer-group effects (see, for example, Feinstein et al. 1999). Thus enrollment $E$, measured as the fraction of children of the respective age group enrolled in formal pre-schools, implies that all children with a family background

$$
f_{i} \geq X=f_{1}-E\left(f_{1}-f_{0}\right)=f_{1}-E \Delta f
$$

attend pre-school, and children with an inferior family background do not.

Given this enrollment pattern, average pre-school peer quality $q$ amounts to: 


$$
q=\frac{f_{1}+X}{2}=\frac{(2-E) f_{1}+E f_{0}}{2}
$$

Denoting the duration of pre-schooling by $K$, we assume that human capital formation in pre-school varies positively with $q$ and $K$. Allowing for decreasing returns in pre-school years $K$, the pre-school production function may be written as $\alpha q K^{\beta}$, where $\alpha$ and $\beta$ are positive parameters and $\beta$ is in the unit interval. Human capital accumulation up to the mandatory school age is of course also directly influenced by the family background; after all, before attending pre-school, children spend most of their prime time at home and are therefore exposed to the family environment (cf. Feinstein et al. 1999). Denoting the beginning of the mandatory school age by $k$, we assume a linear relationship between family background and human capital acquisition at home amounting to $(k-K) f_{i}$.

Before being admitted to school, a child with family background $f_{i}$ has therefore accumulated the human capital:

$$
H_{i}^{K}=\left\{\begin{array}{c}
(k-K) f_{i}+\frac{\alpha}{2}\left[(2-E) f_{1}+E f_{0}\right] K^{\beta}, \quad f_{i} \geq X \Leftrightarrow E \geq \frac{f_{1}-f_{i}}{\Delta f} \\
k f_{i}, \text { otherwise }
\end{array}\right.
$$

Since pre-schooling operates with decreasing returns, whereas human capital accumulation at home is linear in time, it is possible that children acquire less human capital $H^{K}$ if they are sent to pre-school for too long a time. To avoid this pre-school trap that would apply especially to children with favorable family backgrounds, we assume that all children (including the ones with the most favorable family background $f_{1}$ ) profit from attending preschool even if pre-schools offer the worst possible peer-group environment $(E=1)$, i.e. we assume that

$$
H_{f_{1}}^{K}(E=1)-k f_{1}>0 \Leftrightarrow K<\left(\frac{\alpha\left(f_{0}+f_{1}\right)}{2 f_{1}}\right)^{\frac{1}{1-\beta}}=\bar{K}
$$

Figure 1 depicts how much human capital $H^{K}$ children accumulate before they are admitted to school. Children with favorable family backgrounds are advantaged for two reasons: they profit from a better home environment that allows them to accumulate a higher $H_{i}^{K}(K=0)$, and they are sent to formal pre-school which, via assumption (A1), we assume to provide all children with an additional head start.

Marked FBEs on human capital accumulation thus can already be observed at the preschool level. Since the family background $f_{i}$ impacts in a non-linear manner on human capital 
formation, the FBE varies across family backgrounds. If one wants to work with a real-valued indicator capturing the FBE across all children, one therefore needs to resort to some kind of meaningful ad hoc measure. Employing the often used difference between the top and bottom quintile, we base our analysis of the pre-school period on the measure

$$
H_{4 / 5}^{K}-H_{1 / 5}^{K}=\Delta H^{K},
$$

where $H_{z}^{K}$ denotes the human capital accumulated by a child with family background $z=z f_{1}+(1-z) f_{0}$.

Using the above definition of $H^{K}$ one immediately arrives at

$$
\Delta H^{K}=\left\{\begin{array}{c}
\frac{3}{5} k \Delta f, E<\frac{1}{5} \\
(k-K)\left(\frac{4}{5} f_{1}+\frac{1}{5} f_{0}\right)-k\left(\frac{1}{5} f_{1}+\frac{4}{5} f_{0}\right)+\frac{\alpha}{2}\left[(2-E) f_{1}+E f_{0}\right] K^{\beta}, E \in\left[\frac{1}{5}, \frac{4}{5}\right] \\
\frac{3}{5}(k-K) \Delta f, E>\frac{4}{5}
\end{array}\right.
$$

This indicator of pre-school FBEs depends in particular on the duration of formal preschooling $K$ and enrollment $E$. If the children indicated by $z=1 / 5$ are enrolled in pre-school $(E>4 / 5)$, then an increase in the duration of pre-schooling $K$ gives rise to a decrease in $\Delta H^{K}$ because the children are more and more exposed to the same learning environment. If the children indicated by $z=1 / 5$ are not enrolled but the children indicated by $z=4 / 5$ are, i.e. if $E \in[1 / 5,4 / 5)$, then $\Delta H^{K}$ only decreases in $K$ if $K$ is sufficiently large for the decreasing preschool returns to kick in. Differentiating the middle term in the above $\Delta H^{K}$ function with respect to $K$ shows that the resulting differential is negative (for all $E$ ) if and only if

$$
K>\left(\frac{\alpha \beta f_{1}}{f_{4 / 5}}\right)^{\frac{1}{1-\beta}}=\underline{K} .
$$

Adopting assumption (A2), the pre-school FBE as measured by $\Delta H^{K}$ depends on enrollment $E$ as depicted in Figure 2. In the following it will be shown that the implied nonlinear relationship is preserved with minor qualifications all the way through mandatory schooling.

\subsection{Ability Tracking in the School System}

Mandatory schooling lasts for $S$ years. The school system may track children according to ability (which in our model is equal to accumulated human capital) for the last $T \leq S$ years. As 
long as the students are not tracked, they attend for $C=S-T$ years a "comprehensive" school in which all students are exposed to the same peer group environment. Even though the quality of this encompassing peer group environment depends of course on the pre-school experience of the student body, we do not explicitly relate this general peer-group effect to the variables $E$ and $K$ that characterize the pre-school human capital accumulation process. We do however allow for a specific FBE that captures the help school children may obtain from their parents. The associated benefit depends on how much parental help $F_{i}$ (for example, in terms of time) the individual student obtains and on the quality of the help as measured by the family background variable $f_{i}$. The following production function of the comprehensive school portrays how duration of schooling, family help and pre-acquired human capital translate into human capital $H^{C}$ at the end of comprehensive schooling:

$$
H_{i}^{C}=\left(\gamma+F_{i} f_{i}\right) C+H_{i}^{K}
$$

After comprehensive schooling, we envisage a two-tiered school system with a high track accommodating the top $t$ percent of the children (measured according to human capital $H^{C}$ ) and a low track for the remaining students. The high-track school provides the students with more human capital than the low-track school, be it because of a more challenging curriculum or because production profits from a more favorable composition of peers, or both. In any case, we again do not relate possible general peer-group effects to the variables $E, K$ and $C$ describing the students' history, but rather use a parametric specification capturing the main thrust of the argument:

$$
H_{i}^{T}=\delta_{j}(S-C)+H_{i}^{C}
$$

where $j$ denotes either the high-track school $(h)$ or the low-rack school $(l)$, with $\delta_{h}>\delta_{l}$.

In determining the endogenous parental input $F_{i}$ at the comprehensive school level, we assume that parents derive utility only from the publicly revealed success of their children's scholastic experience, i.e. the respective utility gain derives from their children being admitted to the high-track school. We thus focus on status considerations and not on truly altruistic motives associated with academic development. The parents' utility function has the following appearance:

$$
U=T_{j}-C^{2} F_{i}, \quad j=l, h
$$

where $T_{h}\left(T_{l}\right)$ denotes the parents' valuation of the high (low) track school. Notice that we assume increasing marginal cost in the help provided in terms of the duration of 
comprehensive schooling, thereby portraying increasing parental frustration over the long haul. The maximum parental input $F_{i}$ of an $f_{i}$-parent is supplied if this parent is indifferent between providing $F_{i}$ (and thereby managing her child to be admitted to the high-track school) and not providing any effort with the consequence that her child has to attend the lowtrack school, i.e. $T_{l}=T_{h}-C^{2} F_{i}$, or

$$
F_{i}^{\max }=\frac{T_{h}-T_{l}}{C^{2}}=\frac{\Delta T}{C^{2}}
$$

The maximum increase in accumulation of human capital $H^{C}$ attributable to parental input therefore amounts to ${ }^{13}$

$$
F_{i}^{\max } f_{i} C=\frac{\Delta T}{C} f_{i}
$$

Figure 1 depicts the students' increase in human capital attributable to comprehensive schooling, i.e. $\gamma C$, as well as the maximum additional increase attributable to parental input, resulting in the human capital

$$
H_{i}^{C, 0}=H_{i}^{K}+\gamma C \quad \text { or } \quad H_{i}^{C, \max }=H_{i}^{K}+\gamma C+\frac{\Delta T}{C} f_{i},
$$

as the case may be.

We are now in a position to derive the utility maximizing parental input $F_{i}$. To begin with, assume that none of the students obtain any parental help. Then the students with the lowest stock of $H^{C, 0}$ who are admitted to the high-track school have the family background $f_{t}$ (since the top $t$ percent are admitted). Under these circumstances, the parents of the students with family backgrounds just a little less favorable than $f_{t}$ would have an incentive to provide their children with help in order to let them jump over their slightly better qualified school mates. Anticipating this behavior, all parents of students who are in danger of being passed by school mates with less favorable family backgrounds will provide help up to the extent that will deter the parents of the less favored school mates to follow through with their help scheme.

In equilibrium, all students with a family background $f_{i}>f_{t}$ and an anticipated human capital stock net of parental help of less than $H_{t}^{K}+\gamma C+\frac{\Delta T}{C} f_{t}$ will obtain parental help to

13 The parental-help effect could also be interpreted as an incentive effect on the part of the student. From a formal point of view, the two effects are isomorphic. For reasons deriving from introspection we believe however the parental-help interpretation to convey a more realistic portrait of the human capital accumulation process of youths. 
such an extent that they reach exactly the latter critical level. Tracking has therefore two consequences that favor students with favorable family backgrounds: first, they are admitted to the high track schools that offer a better education, and second, they may profit from extra parental help. All these effects are portrayed in Figure 1.

The human capital stock accumulated by the end of the mandatory school age can thus be summarized as follows:

$$
H_{i}^{T}=\left\{\begin{array}{c}
H_{i}^{K}+\gamma C+\delta_{l}(S-C), f_{i}<f_{t} \\
H_{i}^{K}+\gamma C+\delta_{h}(S-C), H_{i}^{K}>H_{t}^{K}+\frac{\Delta T}{C} f_{t} \\
H_{i}^{K}+\gamma C+\frac{\Delta T}{C} f_{t}+\delta_{h}(S-C), \text { otherwise }
\end{array}\right.
$$

Employing the quintile-difference approach to measuring the FBE at the end of mandatory school (assuming that human capital translates into test scores in a linear manner), we arrive at:

$$
\begin{gathered}
F B E=H_{4 / 5}^{T}-H_{1 / 5}^{T}, \quad \text { where } \\
H_{1 / 5}^{T}=H_{1 / 5}^{K}+\gamma C+\delta_{l}(S-C) \text { and } \\
H_{4 / 5}^{T}=\left\{\begin{array}{l}
H_{4 / 5}^{K}+\gamma C+\delta_{h}(S-C), H_{4 / 5}^{K}>H_{t}^{K}+\frac{\Delta T}{C} f_{t} \\
H_{t}^{K}+\gamma C+\frac{\Delta T}{C} f_{t}+\delta_{h}(S-C), \text { otherwise }
\end{array}\right.
\end{gathered}
$$

\subsection{Numerical Solution}

To avoid a straightforward but cumbersome discussion of the properties of the function $\operatorname{FBE}(K, E, C)$, we resort to presenting in Table 4 some numerical examples that provide the general picture.

The non-bracketed entries in Table 4 apply if the parents derive a sizeable utility gain from their children's attending the high-track school $(\Delta T=6)$. The bracketed entries show how the FBEs change if the parents do not derive any such utility gain $(\Delta T=0)$. If pre-school enrollment $E$ is lower than $20 \%$, neither the $f_{4 / 5}$-children nor the $f_{1 / 5}$-children attend preschool; our measure of the FBE which is based on the scholastic achievement of these children then does not depend on how long the few advantaged enrolled children attend preschool. If however enrollment reaches $20 \%$, so that at least the $f_{4 / 5}$-children attend pre-school, the duration $K$ of pre-schooling varies negatively with the FBE, i.e. more years of pre- 
schooling increase equality of opportunity. The reason is that the educational experience of all pre-school children becomes more uniform.

Just as clear-cut is the influence of the timing of segregation as measured by the number $C$ of comprehensive school years. The longer children are educated together, the smaller is the FBE, i.e. comprehensive schooling increases equality of opportunity. One reason is again that comprehensive schools simply provide a uniform educational environment for all children. In addition, however, the parents' educational input becomes more costly as $C$ increases and is therefore reduced; since parental help has an asymmetric influence in the sense that it benefits mainly children with a favorable family background, this second effect reinforces the first one. If pre-school enrollment encompasses $E=60 \%$ of the children of the respective age group and pre-schooling lasts for 15 months $(K=1.25)$, then, if tracking after four years of comprehensive schooling $(C=4)$ is postponed to the end of the sixth year $(C=6)$, the FBE drops from 8.48 to 6.73 . This decrease of 1.75 can be decomposed in a reduction of 1.00 (7.65-6.65) attributable to the increase in comprehensive schooling, and in an additional reduction of 0.75 ((8.48-7.65)-(6.73-6.65)) attributable to the reduction in parental help.

The influence of pre-school enrollment $E$ on the FBE is somewhat more complex. Consider, for example, the first row in Table $4(C=4, K=1.25)$. If only $15 \%$ of the children are enrolled in pre-school, the FBE amounts to 6.55. Since the crucial $f_{4 / 5}$-children do not attend pre-school, their human capital $H^{C}$ is not much higher than that of $f_{1 / 2}$-children, implying that their parents will provide them with help in order to make sure that they eventually are admitted to the prestigious high-track school. This parental input generates an increase of the FBE by 0.45 (without parental help it would be 6.10). An increase in pre-school enrollment to $E=30 \%$ increases the FBE to 7.99. This increase is attributable to the fact that now the $f_{4 / 5}$ children do attend pre-school and therefore have a much higher human capital at the beginning of schooling. Notice that now, the $f_{4 / 5}$-children do not profit anymore from parental help, because they are out of reach for the $f_{1 / 2}$-children who still do not attend pre-school (other children, however, still obtain parental help, but this does not show up in our measure of the FBE). An increase in enrollment from $E=30 \%$ to $E=45 \%$ decreases the FBE because now the peer-group environment at pre-school becomes less favorable. A further increase of enrollment to $E=60 \%$ causes the $\mathrm{FBE}$ to rise again even though the peer-group quality continues to decrease. The reason is that now the $f_{1 / 2}$-children have begun to attend pre-school and therefore are again in a position to contest the sought-after slots at the high-track school, i.e. the parents of the $f_{4 / 5}$-children provide again parental help which accounts for 0.83 (8.48- 
7.65) of the FBE. An enrollment increase to $E=75 \%$ slightly decreases the FBE because of the decrease in pre-school peer quality. But a much more significant drop in the FBE occurs when pre-school enrollment passes the $80 \%$ mark since then also the crucial $f_{1 / 5}$-children attend pre-school, which closes the human capital gap between the two groups of children on which our indicator of the FBE is based.

Our model thus illustrates the conduit through which the most important characteristics of the school system impact the FBE. Late tracking and a long pre-school education are beneficial for equality of opportunity, and pre-school enrollment has a detrimental influence at low levels of enrollment and a beneficial influence at higher levels.

\section{School Systems and Equality of Opportunity: Empirical Evidence}

According to our model, equality of educational opportunity is better achieved in school systems with later tracking and longer pre-school cycles. Pre-school enrollment is predicted to have a non-linear relationship with equality of opportunity as measured by our FBE, which can best be described as an inverted U-shaped curve. Combining the FBEs estimated empirically in Section 2 with country-level data on pre-school and tracking systems, we can test the model predictions empirically. In addition, we will test whether the relationships prove robust when accounting for possible effects of other features of education policies. The results provide answers to the question of why it is that some countries achieve much higher equality of educational opportunity than others.

\subsection{The Empirical Specifications}

There are two ways to identify how systemic features are related to the FBE. First, we can use the estimated country-level FBEs reported in Table 3 directly as left-hand-side variables in regressions on the different systemic features. Second, we can identify the relationship by interacting the country-level systemic features with the individual-level family-background measure in cross-country microeconometric regressions that use the test scores as their dependent variable. We will pursue both avenues of investigation.

\subsubsection{Country-Level Specification}

In the first specification, we use the FBEs estimated in Section 2.3 as the dependent variable in a country-level regression on several country-level systemic features; i.e., the FBE 
estimators $\beta_{j}$ of equation (1) are simply regressed on the set of potentially determining features $Z_{j}$ of the school systems:

$$
\beta_{j}=\lambda+\theta Z_{j}+\mu_{j}
$$

Since the dependent variable in this regression is the outcome of an estimation procedure rather than a precise observation, we have to account for the different standard errors with which the observations of the dependent variable are estimated. The error term from an ordinary-least-squares (OLS) estimation of equation (15) would be heteroscedastic with mean zero and a variance equal to the sum of the variance of the actual error term and the variance of the estimated FBE. We use the weighted estimation procedure proposed by Anderson (1993) which down-weights observations whose FBEs were relatively imprecisely measured: First, we compute the squared residuals of an OLS regression of equation (15). We then run a second regression of these squared residuals on the estimated variances of the FBEs, the variances squared and the variances cubed. The fitted values of this regression specify to what extend the squared residuals of the first regression can be explained by the variance of the FBE estimates. Finally, we use the inverse of these fitted values as weights in a WLS regression of equation (15), thereby giving lower weight to imprecisely estimated FBE observations.

\subsubsection{Student-Level Interaction Specifications}

The country-level specification provides a rather ad-hoc partition of the estimation in two steps: in a first step, equation (1) is estimated using micro data within each country, and a second step then uses the resulting coefficient estimates in the country-level estimation of equation (15). This two-step estimation procedure places rather strong restrictions on the joint distribution of the variables used in the two different equations. We can relax these restrictions by pooling the micro data across countries and combining them with the additional system-level data. In this second set of specifications, the relationship between the country-level systemic features and the effect of family background on student performance can be identified by the interaction between the country-level features and the familybackground measure in a student-level cross-country regression that has the individual test scores as its dependent variable.

The first of these student-level interaction specifications assumes that after having controlled for the observed systemic and individual effects, there is no unobserved heterogeneity left across countries which might bias the estimates. Under this assumption, the 
estimated coefficients $\eta$ on the interaction terms between our family-background proxy $B_{i s j}$ (books at home, measured at the student level) and the vector of systemic features $Z_{j}$ (measured at the country level) identify how the systemic features affect the FBE:

$$
T_{i s j}=\alpha+\beta B_{i s j}+Z_{j} \rho+\left(B_{i s j} Z_{j}\right) \eta+X_{i s j} \gamma+\varpi_{i s j},
$$

where $X_{i s j}$ is a vector combining all the (student-level) control variables of equation (1).

This specification does not only identify how the FBEs relate to the systemic features, but also the main effects of the systemic features on student test scores. However, the estimates of these main systemic effects in equation (16) will only be unbiased if there is no unobserved heterogeneity in the performance levels across the countries. Thus, this first student-level interaction specification still requires the assumption that there is no unobserved crosscountry heterogeneity in student performance.

We can relax this assumption in a second student-level interaction specification that introduces a whole set of country fixed effects $C_{j}$, as well as interaction effects between all student-level controls $X_{i s j}$ and the country fixed effects:

$$
T_{i s j}=\alpha+\beta B_{i s j}+\left(B_{i s j} Z_{j}\right) \eta+C_{j} \delta_{1}+\left(C_{j} X_{i s j}\right) \delta_{2}+X_{i s j} \gamma+\varpi_{i s j} .
$$

Due to the inclusion of country fixed effects, this specification can no longer identify the main systemic effects that work at the country level. But despite the country fixed effect, the specification still identifies our main measure of interest, namely how the systemic features affect the FBE. This influence is captured by the coefficients $\eta$ on the interaction terms at the student level.

For the identification of equation (17), the assumption of no unobserved cross-country heterogeneity can be replaced by the less restrictive assumption that any unobserved crosscountry heterogeneity that may exist is unrelated to the size of the FBEs. Under this assumption, equation (17) can still identify how education policies relate to equality of educational opportunity. Since it requires the least restrictive assumptions on the crosscountry distribution of test scores, the student-level interaction specification with country fixed effects of equation (17) is our preferred specification.

When estimating the student-level specifications of equations (16) and (17), one has to be aware that one part of the measures which identify our effect of interest, namely the systemic features of the school systems, are measured at the country level rather than the school level, since education policies are observed as system-level variables that vary across countries. Thus, the Moulton (1986) problem of a hierarchical data structure now applies at the country 
rather than the school level, requiring a higher-level (country) error component to avoid spurious results. We therefore use countries as PSUs in the CRLR estimation of equations (16) and (17), allowing any given interdependence of the error variance-covariance matrix within countries and requiring only that the observations are independent across countries. This basically means that the standard errors are measured as if there were only as many observations as there are countries in the regression. Furthermore, in addition to the withincountry weighting of students according to their sampling weights (cf. Section 2.2 above), the observations are now weighted across countries such that each country in the sample has equal weight.

\subsection{Results on the Effect of Education Policy on Educational Inequality}

Country-level data on the different features of the school systems $Z$ mainly come from statistical yearbooks and data collections by international organizations such as UNESCO and OECD, as well as detailed country-specific inquiries. Table A1 in the Appendix provides details on the definitions and sources of the different variables. The information was specifically collected for the years relevant for the students tested in the two TIMSS tests in 1995 and 1999. Descriptive statistics of the data are contained in Table 2.

We use the theoretical model of Section 3 as our baseline model for each of the three empirical specifications. ${ }^{14}$ The results of the country-level specification are reported in Table 5, the student-level interaction specification with main systemic effects in Table 6 and the student-level interaction specification with country fixed effects in Table 7. The baseline model of each specification, reported in columns (1), (3) and (5) of Tables 5-7, includes the age of first tracking, enrollment in pre-school education and its square and the duration of pre-school education as potential determinants of the size of the FBE.

The age at which students are first tracked into different school types that serve students according to their ability varies considerably across countries. While school tracking in many countries does not occur at all before the age of the students tested in TIMSS (roughly 14 years), it occurs as early as age 10 in other countries. In line with the predictions of our model, later tracking is found to be statistically significantly negatively related to the FBEs in all three empirical specifications. That is, the earlier an education system tracks its students into different types of schools according to their ability, the more unequal are educational

\footnotetext{
14 Taiwan could not be included in any of the estimations due to lack of internationally comparable information on several school-system variables.
} 
opportunities. While the systemic effect is directly estimated in the country-level specification of Table 5, where the FBE is the dependent variable, the systemic effect in the two studentlevel specifications is identified by the interaction effect. Under the assumption that there is no bias due to unobserved country heterogeneity, the student-level interaction specification with main systemic effects of Table 6 yields also estimates of the main effects of the systemic features on student performance. The results suggest that tracking does not exert a statistically significant direct effect on student performance.

Table 7 reports the results of our preferred specification, which not only controls for a complete set of country fixed effects, but also for interaction effects between each of the student-level control variables and the complete set of country dummies, allowing the effects of the student-level controls to be country-specific. The size of the estimated interaction effect in column (5) suggests that for each additional year of earlier tracking, the estimated FBE (which has an international mean of 17.5 across all countries) increases by slightly more than one unit. Thus, a difference in the age of first tracking of four years is related to a difference in the FBE of an order of magnitude of roughly one quarter of the international mean of the whole FBE. The tracking effect is also directly observable in our estimated FBEs (Table 3). In our sample of countries, the education systems that track their students as early as age 10 Austria (with an estimated FBE of 20.8), Germany (25.6), Hungary (25.8) and the Slovak Republic (24.0) - all show relatively large FBEs. By contrast, none of the OECD countries with relatively low FBEs - France (8.3), Canada (9.8) and Portugal (10.4) - track before an age of 15. The estimated tracking effect of column (5) in Table 7 suggests that roughly one third of the 14.5-point difference in the FBE between these two groups of countries can be attributed to their divergent tracking policies.

In all three empirical specifications (Tables 5-7), the relationship between the FBE and the enrollment share in pre-school education follows a statistically significant inverted U-shaped pattern, again strongly in line with the theoretical model. That is, as long as only a relatively small part of the student population is enrolled in pre-school, enrollment is positively related to the FBE, which may be due to unequalizing effects of non-random sorting of better-off students into pre-school. Only when a substantial share of students is enrolled in pre-school, so that less well-off students are also enrolled, do we find an equalizing effect of pre-school enrollment. Figure 3 depicts this non-linear pattern graphically. Educational opportunities get more unequal with rising pre-school enrollment up to a maximum of 61 percent of pre-school enrollment. Only beyond this threshold is higher pre-school enrollment associated with more 
equal educational opportunities. As is evident from the figure, moving from a low pre-school enrollment of 20 percent to a medium enrollment of 60 percent increases the estimated FBE by roughly 5 units. Moving from 60 percent enrollment to full enrollment decreases the estimated FBE by about the same amount.

Also in line with the predictions of our model, we find that the official duration of preschool education is statistically significantly negatively related to the estimated FBEs in all three empirical specifications. A longer pre-school cycle is associated with lower inequality of educational opportunity. While pre-school enrollment - like tracking - does not show a statistically significant direct effect on student performance in the specification with main systemic effects of Table 6, meaning that these systemic features exert their impact on student performance only through an indirect effect via family background, the duration of the preschool cycle shows an additional statistically significant positive direct effect on the level of student performance.

The predictions of our theoretical model are empirically borne out in all three empirical specifications: There is a negative relationship of the FBE with age of first tracking and preschool duration, and an inverted U-shaped relationship between FBE and pre-school enrollment. In the country-level model of Table 5, these features of the education system can together account for 40 percent of the cross-country variation in our estimated FBEs.

To test for the robustness of these findings and check for other potentially important effects, we extend the baseline model to include additional explanatory variables in columns (2), (4) and (6) of Tables 5-7. In the first and third specification, neither educational expenditure per student nor the gross national income (GNI) per capita are statistically significantly related to the FBEs. ${ }^{15}$ The country-specific mean test-score performance, however, has a statistically significant and positive relationship with the FBEs. ${ }^{16}$ In the specification with main systemic effects of Table 6, the GNI per capita displays a marginally significant negative interaction with family background, as well as a marginally significant positive direct relationship with student performance. Most importantly, the results for the features of the baseline model remain qualitatively the same in the extended model.

In column (7) of Table 7, we introduce two further systemic features of the education systems, namely the proportion of educational funds that stem from private sources and the

\footnotetext{
15 Unfortunately, we do not have data on the within-country variance in educational expenditure.

16 To preserve the main-effects character of the specification of the first student-level specification, column (4) does not include the country mean test-score performance, as this would add aggregate values of the lefthand-side variable to the right-hand side.
} 
share of enrollment in private schools. While the number of available country observations drops to 27 in this specification, the results still show statistically significant relationships between the FBE and the share of the private sector in educational expenditure and enrollment. They suggest that the FBE increases with private expenditure and decreases with private enrollment. That is, education systems that rely on private funding show larger inequality of educational opportunity, but more private schooling provision relates to decreased inequality of opportunity.

The results so far are based on samples that include all countries for which the data are available. To make sure that they are not driven by variations between very heterogeneous countries, Table 8 re-estimates the student-level interaction specification with country fixed effects for the more homogeneous sample of OECD countries. All substantive results prove robust in the OECD sample. The only exception is the effect of the country mean test score on the FBEs, which is now statistically insignificant and negative. That is, the tradeoff between equality of opportunity and a country's mean performance apparent in the previous specifications does not survive the scrutiny of the OECD sample. Countries that achieve a higher degree of equality of educational opportunity do not seem to have to compromise on the average performance level of their student population.

As a further robustness check, we drop France and Japan from our sample of countries, because they did not provide data on parental immigration status (and France also not on student immigration status), which might affect the relative size of their estimated FBEs. ${ }^{17}$ Again, our results are not sensitive to this reduction in sample size (details available from the authors).

We also experimented with two further systemic features of the education systems, namely half-day versus full-day schooling and the age at which compulsory education starts. A dummy for full-day schooling (available for 34 countries) is not statistically significantly related to the FBEs in any of our specifications. However, any effect of full-day schooling may be difficult to detect, since our data do not distinguish between countries that have afternoon classes and countries that only provide optional day care. The relationship between the FBE and the starting age of compulsory education proves very sensitive, mainly because

17 In Tables 6-8, the immigration dummies in the two countries were set to 1 ; in our preferred specification, any systematic effect that this constant imputation might have relative to other countries would be captured by the country fixed effects. 
the starting age does not show much variation across countries (lying between 5 and 7 years) and because effects of pre-school enrollment and duration are already controlled for.

\section{Conclusion}

In this paper, we developed an index of the inequality of educational opportunity in 54 countries, based on estimates of the effect of family background on students' educational performance. The family-background effects (FBEs) reveal substantial variation in the extent to which different countries achieve equality of educational opportunity for children from different family backgrounds.

In order to explain how the family-background influence is related to systemic features of countries' education systems, we presented a model that predicts that the earlier an education system tracks its students into different school types, the larger are the performance differences along the family-background dimension. The FBEs were predicted first to increase with enrollment in pre-school education and then - after an enrollment ratio of slightly more than half of the student population - to decrease with enrollment in pre-school education. Also, longer pre-school cycles were predicted to decrease the FBEs. Thus, systems of extensive early-childhood education and comprehensive schooling were supposed to increase equality of educational opportunity.

Our empirical results suggest that the model describes the relationship between a country's education policies and the extent to which the country achieves equality of educational opportunity very well. Different specifications consistently indicate the importance of extensive early-childhood education and late tracking. Apart from the variables captured by the model, we also tested the effects of several other systemic features on the FBEs. The estimated FBEs increase with the share of private expenditure in total educational expenditure, but decrease with the share of privately managed schools. By contrast, several other country-specific features do not seem to be significantly related to the degree of equality of educational opportunity achieved. This is true for the level of educational expenditure, GNI per capita, the length of the average school day and the official school starting age. In the sample of OECD countries, there is also no evidence for an efficiency-equity tradeoff in education, in the sense that more equal education systems would systematically show lower mean performance of their students. 


\section{References}

Anderson, Patricia M. (1993). Linear Adjustment Costs and Seasonal Labor Demand: Evidence from Retail Trade Firms. Quarterly Journal of Economics, 108 (4): 1015-1042.

Barnett, Steven W. (1992). Benefits of Compulsory Preschool Education. Journal of Human Resources 27 (2): 279-312.

Beaton, Albert E., Ina V.S. Mullis, et al. (1996). Mathematics Achievement in the Middle School Years: IEA's Third International Mathematics and Science Study (TIMSS). Chestnut Hill, MA: Boston College.

Betts, Julian R., Jamie L. Shkolnik (2000). The Effects of Ability Grouping on Student Achievement and Resource Allocation in Secondary Schools. Economics of Education Review 19 (1): 1-15.

Chiswick, Barry, Noyna DebBurman (2004). Pre-School Enrolment: An Analysis by Immigrant Generation. IZA Discussion Paper 1226. Bonn: Institute for the Study of Labor.

Currie, Janet (2001). Early Childhood Education Programs. Journal of Economic Perspectives 15 (2): 213-238.

Deaton, Angus (1997). The Analysis of Household Surveys: A Microeconometric Approach to Development Policy. Baltimore: The Johns Hopkins University Press.

DuMouchel, William H., Greg J. Duncan (1983). Using Sample Survey Weights in Multiple Regression Analyses of Stratified Samples. Journal of the American Statistical Association 78 (383): 535-543.

Epple, Dennis, Elizabeth Newlon, Richard Romano (2002). Ability Tracking, School Competition, and the Distribution of Educational Benefits. Journal of Public Economics 83 (1): 1-48.

European Commission (1999, 2000). Key Data on Education in Europe. Luxembourg: Office for Official Publications of the European Communities.

Feinstein, Leon, Donald Robertson, James Symons (1999). Pre-School Education and Attainment in the National Child Development Study and British Cohort Study. Education Economics 7 (3): 209-234.

Figlio, David N., Marianne E. Page (2002). School Choice and the Distributional Effects of Ability Tracking: Does Separation Increase Inequality? Journal of Urban Economics 51 (3): 497-514.

Fuchs, Thomas, Ludger Wößmann (2004). What Accounts for International Differences in Student Performance? A Re-examination using PISA Data. CESifo Working Paper 1235. Munich: CESifo.

Galindo-Rueda, Fernando, Anna Vignoles (2005). The Heterogeneous Effect of Selection in UK Secondary Schools. Revised version of a paper presented at the CESifo/PEPG conference on "Schooling and Human Capital Formation in the Global Economy" in Munich. London School of Economics, Mimeo.

Ganzeboom, Harry B. G., Paul M. De Graaf, Donald J. Treiman (1992). A Standard International Socio-Economic Index of Occupational Status. Social Science Research 21 (1): 1-56.

Garces, Eliana, Duncan Thomas, Janet Currie (2002). Longer-Term Effects of Head Start. American Economic Review 92 (4): 999-1012.

Gonzalez, Eugenio J., Julie A. Miles (eds.) (2001). User Guide for the TIMSS 1999 International Database. Chestnut Hill, MA: Boston College. 
Gonzalez, Eugenio J., Teresa A. Smith (eds.) (1997). User Guide for the TIMSS International Database: Primary and Middle School Years. Chestnut Hill, MA: Boston College.

Hanushek, Eric A., Ludger Wößmann (2005). Does Educational Tracking Affect Performance and Inequality? Differences-in-Differences Evidence across Countries. NBER Working Paper 11124. Cambridge, MA: National Bureau of Economic Research.

Magnuson, Katherine A., Christopher J. Ruhm, Jane Waldfogel (2004). Does Prekindergarten Improve School Preparation and Performance? NBER Working Paper 10452. Cambridge, MA: National Bureau of Economic Research.

Martin, Michael O., Dana L. Kelly (eds.) (1996). Third International Mathematics and Science Study Technical Report, Volume I: Design and Development. Chestnut Hill, MA: Boston College.

Martin, Michael O., Dana L. Kelly (eds.) (1997). Third International Mathematics and Science Study Technical Report, Volume II: Implementation and Analysis - Primary and Middle School Years. Chestnut Hill, MA: Boston College.

Martin, Michael O., Kelvin D. Gregory, Steven E. Stemler (eds.) (2000). TIMSS 1999 Technical Report. Chestnut Hill, MA: Boston College.

Meghir, Costas, Mårten Palme (2005). Educational Reform, Ability, and Family Background. American Economic Review 95 (1): 414-424.

Moulton, Brent R. (1986). Random Group Effects and the Precision of Regression Estimates. Journal of Econometrics 32 (3): 385-397.

Mullis, Ina V.S., Michael O. Martin, et al. (2000). TIMSS 1999 International Mathematics Report: Findings from IEA's Repeat of the Third International Mathematics and Science Study at the Eighth Grade. Chestnut Hill, MA: Boston College.

Nickell, Stephen (2004). Poverty and Worklessness in Britain. Economic Journal 114 (494): C1-C25.

Organisation for Economic Co-Operation and Development (OECD) (2002). Education at a Glance: OECD Indicators 2002. Paris: OECD.

Renz, Monika (1994). Ganztagsschule in anderen EG-Ländern. Wie sieht die Realität aus? Die Ganztagsschule (1/2).

Schweinhart, Lawrence J., J. Montie, Z. Xiang, W.S. Barnett, C.R. Belfield, M. Nores (2005). Lifetime Effects: The High/Scope Perry Preschool Study Through age 40. Monographs of the High/Scope Educational Research Foundation, 14. Ypsilanti, MI: High/Scope Press.

United Nations Educational, Scientific and Cultural Organization (UNESCO) (1998, 2000). World Education Report. Paris: UNESCO Publishing.

UNESCO Institute for Statistics (2003). Data on National Education Systems. http://www.uis.unesco.org/pagesen/DBSysCri.asp (05.12.2003).

White, Halbert (1984). Asymptotic Theory for Econometricians. Orlando: Academic Press.

Wooldridge, Jeffrey M. (2001). Asymptotic Properties of Weighted M-Estimators for Standard Stratified Samples. Econometric Theory 17 (2): 451-470.

World Bank (2005). World Development Indicators. http://devdata.worldbank.org/dataonline

Wößmann, Ludger (2003). Schooling Resources, Educational Institutions and Student Performance: The International Evidence. Oxford Bulletin of Economics and Statistics 65 (2): 117-170.

Wößmann, Ludger (2004). How Equal Are Educational Opportunities? Family Background and Student Achievement in Europe and the United States. CESifo Working Paper 1162. Munich: CESifo. 


\section{Appendix}

Table A1: Definition and Source of Data

\begin{tabular}{|c|c|c|}
\hline Variable & Definition and Year of Observation & Source \\
\hline Age of first tracking & $\begin{array}{l}\text { Age of students at the time of first streaming, different } \\
\text { years since } 1999\end{array}$ & $\begin{array}{l}\text { European Commission } \\
(1999,2000), \text { detailed } \\
\text { country-specific inquiries }\end{array}$ \\
\hline Pre-school enrollment & $\begin{array}{l}\text { Gross enrollment rate in pre-primary education, } 1987 \\
\text { and 1991, respectively }\end{array}$ & $\begin{array}{l}\text { UNESCO Institute for } \\
\text { Statistics (2003) }\end{array}$ \\
\hline Pre-school duration & $\begin{array}{l}\text { Duration of pre-primary education, } 1988 \text { and 1992, } \\
\text { respectively }\end{array}$ & $\begin{array}{l}\text { UNESCO Institute for } \\
\text { Statistics (2003) }\end{array}$ \\
\hline $\begin{array}{l}\text { Educational expenditure } \\
\text { per student }\end{array}$ & $\begin{array}{l}\text { Current expenditure per student in pre-primary, primary } \\
\text { and secondary schooling, } 1995\end{array}$ & UNESCO $(1998,2000)$ \\
\hline GNI per capita & $\begin{array}{l}\text { GNI per capita in PPP (current international \$), } 1995 \text { and } \\
\text { 1999, respectively }\end{array}$ & $\begin{array}{l}\text { World Development } \\
\text { Indicators database }\end{array}$ \\
\hline Private expenditure share & $\begin{array}{l}\text { Proportion of private sources of funds for educational } \\
\text { institutions (after transfers from public sources), all } \\
\text { levels of education, } 1999\end{array}$ & $\begin{array}{l}\text { OECD (2002: 212), } \\
\text { Table B4.1 }\end{array}$ \\
\hline Private enrollment share & $\begin{array}{l}\text { Private enrollment as percentage of total enrollment, } \\
\text { general secondary education, } 1995 \text { and 1996, resp. }\end{array}$ & UNESCO $(1998,2000)$ \\
\hline Full-day schooling & $\begin{array}{l}\text { Dummy: } 1 \text { if in the respective country, full-time } \\
\text { schooling is the rule, different years since } 1999\end{array}$ & $\begin{array}{l}\text { Renz (1994), detailed } \\
\text { country-specific inquiries }\end{array}$ \\
\hline Start of primary education & $\begin{array}{l}\text { Age of students at start of primary education, } 1988 \text { and } \\
\text { 1992, respectively }\end{array}$ & $\begin{array}{l}\text { UNESCO Institute for } \\
\text { Statistics (2003) }\end{array}$ \\
\hline
\end{tabular}


Table 1: Educational Performance and Family Background by Country

\begin{tabular}{|c|c|c|c|c|c|c|c|c|}
\hline & \multicolumn{2}{|c|}{ TIMSS performance } & \multirow[b]{2}{*}{$1(0-10)$} & \multicolumn{4}{|c|}{ Books at home $^{\mathrm{a}}$} & \multirow{2}{*}{$\begin{array}{c}\text { Mean } \\
\text { category }\end{array}$} \\
\hline & Mean & SD & & $2(11-25)$ & $3(26-100)$ & $4(101-200)$ & $5(200+)$ & \\
\hline Australia & 541.4 & 87.1 & 3.3 & 7.0 & 24.0 & 25.8 & 40.0 & 3.9 \\
\hline Austria & 546.9 & 88.7 & 10.5 & 17.5 & 31.4 & 16.7 & 23.8 & 3.3 \\
\hline Belgium (Flemish) & 558.2 & 73.3 & 14.6 & 19.4 & 32.1 & 16.1 & 17.7 & 3.0 \\
\hline Belgium (French) & 494.9 & 78.7 & 6.9 & 10.2 & 28.0 & 20.7 & 34.2 & 3.7 \\
\hline Bulgaria & 529.2 & 83.1 & 8.7 & 11.6 & 23.8 & 19.2 & 36.6 & 3.6 \\
\hline Canada & 537.0 & 75.6 & 4.5 & 10.8 & 28.1 & 24.6 & 31.9 & 3.7 \\
\hline Chile & 423.4 & 78.2 & 20.0 & 31.6 & 28.2 & 11.0 & 9.2 & 2.6 \\
\hline Colombia & 390.5 & 62.4 & 25.6 & 31.5 & 26.6 & 9.0 & 7.3 & 2.4 \\
\hline Cyprus & 474.3 & 79.3 & 5.4 & 18.4 & 35.0 & 22.9 & 18.3 & 3.3 \\
\hline Czech Republic & 555.7 & 79.5 & 0.8 & 5.8 & 31.9 & 30.7 & 30.9 & 3.9 \\
\hline Denmark & 486.4 & 78.3 & 3.3 & 8.5 & 30.0 & 21.1 & 37.1 & 3.8 \\
\hline England & 530.0 & 87.3 & 6.0 & 13.0 & 29.4 & 22.6 & 28.9 & 3.6 \\
\hline Finland & 543.5 & 65.4 & 3.5 & 14.0 & 38.7 & 21.9 & 21.9 & 3.4 \\
\hline France & 514.9 & 67.5 & 5.4 & 17.1 & 36.4 & 21.1 & 19.9 & 3.3 \\
\hline Germany & 517.5 & 89.3 & 8.1 & 13.8 & 26.2 & 18.8 & 33.1 & 3.5 \\
\hline Greece & 486.8 & 80.0 & 5.0 & 22.3 & 42.7 & 18.2 & 11.8 & 3.1 \\
\hline Hong Kong & 562.1 & 77.7 & 24.8 & 28.3 & 28.2 & 9.6 & 9.1 & 2.5 \\
\hline Hungary & 550.6 & 82.0 & 3.5 & 10.1 & 25.1 & 41.0 & 39.9 & 3.8 \\
\hline Iceland & 486.3 & 70.5 & 0.7 & 5.2 & 29.0 & 28.4 & 36.7 & 4.0 \\
\hline Indonesia & 433.2 & 86.5 & 25.7 & 38.6 & 25.8 & 5.3 & 4.5 & 2.2 \\
\hline Iran & 447.6 & 68.0 & 33.2 & 32.3 & 19.5 & 7.1 & 8.0 & 2.2 \\
\hline Ireland & 530.4 & 87.2 & 7.1 & 16.1 & 33.8 & 21.1 & 21.8 & 3.3 \\
\hline Israel & 501.9 & 94.1 & 4.8 & 15.6 & 32.3 & 23.6 & 23.7 & 3.4 \\
\hline Italy & 502.0 & 80.8 & 12.1 & 25.2 & 27.7 & 14.8 & 20.2 & 3.1 \\
\hline Japan & 583.5 & 80.4 & 13.9 & 19.4 & 31.2 & 18.0 & 17.5 & 3.1 \\
\hline Jordan & 455.1 & 94.8 & 21.3 & 30.5 & 28.4 & 29.7 & 10.0 & 2.6 \\
\hline Korea & 584.7 & 85.5 & 9.7 & 11.2 & 34.8 & 23.4 & 20.8 & 3.3 \\
\hline Kuwait & 403.9 & 57.0 & 22.3 & 26.8 & 38.3 & 10.2 & 12.5 & 2.6 \\
\hline Latvia & 501.6 & 74.0 & 1.4 & 5.2 & 18.7 & 23.1 & 51.6 & 4.2 \\
\hline Lithuania & 485.4 & 75.2 & 4.9 & 18.2 & 35.5 & 20.8 & 20.6 & 3.3 \\
\hline Macedonia & 467.9 & 87.1 & 15.4 & 38.1 & 30.0 & 9.1 & 7.3 & 2.5 \\
\hline Malaysia & 520.4 & 74.0 & 13.0 & 34.1 & 32.3 & 12.0 & 8.8 & 2.7 \\
\hline Moldova & 478.5 & 82.4 & 20.2 & 32.7 & 27.5 & 11.0 & 8.5 & 2.5 \\
\hline Morocco & 344.1 & 81.2 & 37.4 & 35.2 & 39.7 & 4.9 & 3.0 & 2.0 \\
\hline Netherlands & 552.2 & 73.8 & 8.0 & 15.7 & 32.1 & 21.0 & 23.1 & 3.4 \\
\hline New Zealand & 514.9 & 85.4 & 4.4 & 8.7 & 25.7 & 24.6 & 36.6 & 3.8 \\
\hline Norway & 512.3 & 78.3 & 2.3 & 5.7 & 25.2 & 22.9 & 45.0 & 4.0 \\
\hline Philippines & 376.4 & 93.7 & 37.4 & 30.5 & 19.3 & 6.2 & 6.5 & 2.1 \\
\hline Portugal & 462.3 & 61.3 & 10.4 & 26.2 & 31.6 & 14.5 & 17.3 & 3.0 \\
\hline Romania & 483.4 & 88.8 & 19.1 & 22.8 & 25.6 & 13.2 & 19.4 & 2.9 \\
\hline Russian Federation & 539.0 & 84.7 & 3.1 & 12.0 & 33.2 & 26.7 & 24.9 & 3.6 \\
\hline Scotland & 504.7 & 86.5 & 11.2 & 17.3 & 28.2 & 18.7 & 24.7 & 3.3 \\
\hline Singapore & 613.4 & 83.0 & 11.8 & 22.0 & 40.6 & 13.8 & 11.8 & 2.9 \\
\hline Slovak Republic & 546.6 & 77.9 & 2.1 & 12.5 & 43.7 & 23.8 & 17.8 & 3.4 \\
\hline Slovenia & 547.8 & 78.5 & 3.1 & 15.8 & 42.1 & 21.1 & 17.9 & 3.3 \\
\hline South Africa & 480.6 & 97.3 & 38.9 & 29.3 & 15.5 & 6.6 & 9.6 & 2.2 \\
\hline Spain & 498.8 & 68.1 & 3.7 & 18.4 & 32.5 & 19.7 & 25.8 & 3.5 \\
\hline Sweden & 524.5 & 80.5 & 3.1 & 8.0 & 24.3 & 23.9 & 40.7 & 3.9 \\
\hline Switzerland & 531.4 & 81.9 & 7.9 & 16.2 & 30.3 & 20.1 & 25.5 & 3.4 \\
\hline Taiwan (Chinese Taipei) & 592.8 & 90.2 & 17.5 & 23.2 & 31.2 & 11.9 & 16.3 & 2.9 \\
\hline Thailand & 505.9 & 74.2 & 20.1 & 33.7 & 30.1 & 8.6 & 7.5 & 2.5 \\
\hline Tunisia & 452.5 & 56.9 & 21.4 & 35.9 & 24.5 & 9.3 & 8.9 & 2.5 \\
\hline Turkey & 446.8 & 73.3 & 21.6 & 36.7 & 27.6 & 8.2 & 5.9 & 2.4 \\
\hline United States & 518.9 & 89.2 & 8.1 & 13.2 & 28.3 & 21.0 & 29.4 & 3.5 \\
\hline
\end{tabular}

Notes: Mean performance: TIMSS-95/TIMSS-Repeat international test score (mean of math and science), re-scaled, weighted by sampling probabilities. - SD: Standard deviation of the TIMSS-95/TIMSS-Repeat international test score. - Books at home: share of students in each category, weighted by sampling probabilities. $-{ }^{\mathrm{a}} 1=$ none or very few $(0-10$ books $) ; 2=$ enough to fill one shelf (11-25 books); 3 = enough to fill one bookcase (26-100 books); 4 = enough to fill two bookcases (101-200 books); 5 = enough to fill three or more bookcases (more than 200 books). - Mean category: mean of the books-at-home categories (1-5). OECD member states marked in bold. 
Table 2: Descriptive Statistics of the International Data

\begin{tabular}{|c|c|c|c|c|c|}
\hline & Mean & $\begin{array}{l}\text { Standard } \\
\text { deviation }\end{array}$ & Minimum & Maximum & $\begin{array}{c}\text { Number of } \\
\text { countries }\end{array}$ \\
\hline Books at home (1-5) & 3.2 & 1.3 & 1 & 5 & 54 \\
\hline Student age $^{\mathrm{a}}$ & 14.3 & 0.8 & 13 & 17.3 & 54 \\
\hline Female student & 0.499 & & 0 & 1 & 54 \\
\hline Living with both parents & 0.838 & & 0 & 1 & 51 \\
\hline Student born in country & 0.938 & & 0 & 1 & 52 \\
\hline Mother born in country & 0.892 & & 0 & 1 & 53 \\
\hline Father born in country & 0.886 & & 0 & 1 & 53 \\
\hline Age of first tracking & 15.2 & 2.5 & 10 & 19 & 54 \\
\hline Pre-school enrollment & 60.1 & 29.4 & 5.1 & 115.9 & 53 \\
\hline Pre-school duration & 2.7 & 1.0 & 1 & 4 & 53 \\
\hline Educational expenditure per student & 4380.7 & 3874.9 & 189 & 14270.4 & 50 \\
\hline GNI per capita & 14584.2 & 8020.8 & 1300 & 33160 & 53 \\
\hline Private enrollment share & 15.1 & 20.0 & 0 & 77.5 & 43 \\
\hline Private expenditure share & 13.7 & 11.5 & 1.2 & 44.9 & 32 \\
\hline Full-day schooling & 0.559 & & 0 & 1 & 34 \\
\hline Start of primary education & 6.2 & 0.5 & 5 & 7 & 53 \\
\hline
\end{tabular}

Notes: Mean: International mean, weighted by sampling probabilities. - Standard deviation: International standard deviation (only for discrete variables). $-{ }^{\text {a }}$ Minimum and maximum are $1^{\text {st }}$ and $99^{\text {th }}$ percentile, respectively. 
Table 3: Family-Background Effects (FBEs) as an Index of Inequality of Educational Opportunity

\begin{tabular}{|c|c|c|c|c|c|}
\hline & & FBE & Std. Err. & Year(s) & Observations \\
\hline 1 & England & 28.81 & (1.70) & $1995+1999$ & 4,388 \\
\hline 2 & Taiwan (Chinese Taipei) & 27.91 & (1.31) & 1999 & 5,711 \\
\hline 3 & Scotland & 26.95 & $(1.70)$ & 1995 & 2,608 \\
\hline 4 & Hungary & 25.84 & (1.29) & $1995+1999$ & 5,727 \\
\hline 5 & Germany & 25.57 & (1.94) & 1995 & 2,698 \\
\hline 6 & Korea & 24.75 & $(0.81)$ & $1995+1999$ & 8,897 \\
\hline 7 & Macedonia & 24.05 & (2.35) & 1999 & 3,683 \\
\hline 8 & Slovak Rep. & 24.01 & (1.26) & $1995+1999$ & 6,823 \\
\hline 9 & Bulgaria & 23.32 & (2.94) & 1999 & 3,107 \\
\hline 10 & United States & 23.13 & $(0.81)$ & $1995+1999$ & 14,877 \\
\hline 11 & Lithuania & 23.09 & (1.32) & $1995+1999$ & 4,749 \\
\hline 12 & Ireland & 23.04 & (1.98) & 1995 & 2,989 \\
\hline 13 & New Zealand & 22.80 & $(1.40)$ & $1995+1999$ & 6,974 \\
\hline 14 & Czech Rep. & 22.45 & (1.67) & $1995+1999$ & 6,604 \\
\hline 15 & Slovenia & 22.25 & (1.51) & $1995+1999$ & 5,676 \\
\hline 16 & Malaysia & 22.18 & (2.06) & 1999 & 5,524 \\
\hline 17 & South Africa & 22.05 & (2.67) & $1995+1999$ & 10,307 \\
\hline 18 & Chile & 21.95 & (1.78) & 1999 & 5,507 \\
\hline 19 & Australia & 21.45 & (1.43) & $1995+1999$ & 10,454 \\
\hline 20 & Sweden & 21.24 & (1.59) & 1995 & 3,925 \\
\hline 21 & Austria & 20.80 & (1.68) & 1995 & 2,632 \\
\hline 22 & Russian Fed. & 20.27 & $(1.78)$ & $1995+1999$ & 7,941 \\
\hline 23 & Norway & 20.00 & (1.68) & 1995 & 3,196 \\
\hline 24 & Romania & 19.68 & (2.09) & $1995+1999$ & 6,748 \\
\hline 25 & Greece & 19.22 & (1.63) & 1995 & 3,898 \\
\hline 26 & Israel & 18.84 & (2.17) & $1995+1999$ & 4,965 \\
\hline 27 & Singapore & 18.54 & (1.82) & $1995+1999$ & 9,518 \\
\hline 28 & Jordan & 17.92 & $(2.40)$ & 1999 & 4,402 \\
\hline 29 & Italy & 17.51 & $(1.42)$ & 1999 & 3,300 \\
\hline 30 & Netherlands & 17.03 & (2.08) & $1995+1999$ & 4,729 \\
\hline 31 & Belgium (French) & 16.77 & (1.77) & 1995 & 2,477 \\
\hline 32 & Switzerland & 16.77 & (1.62) & 1995 & 4,720 \\
\hline 33 & Latvia & 16.65 & $(1.26)$ & $1995+1999$ & 4,939 \\
\hline 34 & Philippines & 16.53 & (2.09) & $1995+1999$ & 11,693 \\
\hline 35 & Moldova & 15.80 & (2.01) & 1999 & 3,342 \\
\hline 36 & Spain & 15.26 & $(1.06)$ & 1995 & 3,752 \\
\hline 37 & Denmark & 15.08 & (1.62) & 1995 & 2,155 \\
\hline 38 & Cyprus & 14.21 & (0.89) & $1995+1999$ & 5,680 \\
\hline 39 & Finland & 13.98 & (1.51) & 1999 & 2,828 \\
\hline 40 & Japan & 13.50 & (1.13) & $1999^{\mathrm{a}}$ & 4,608 \\
\hline 41 & Thailand & 12.37 & $(1.60)$ & $1995+1999$ & 11,211 \\
\hline 42 & Turkey & 11.77 & (1.35) & 1999 & 7,393 \\
\hline 43 & Iceland & 11.42 & (2.55) & 1995 & 1,728 \\
\hline 44 & Iran & 11.25 & (0.93) & $1995+1999$ & 7,231 \\
\hline 45 & Belgium (Flemish) & 10.95 & (1.11) & $1995+1999$ & 7,657 \\
\hline 46 & Hong Kong & 10.82 & $(1.28)$ & $1995+1999$ & 7,984 \\
\hline 47 & Portugal & 10.40 & (1.05) & 1995 & 3,335 \\
\hline 48 & Canada & 9.76 & $(0.95)$ & $1995+1999$ & 16,101 \\
\hline 49 & France & 8.32 & (1.44) & 1995 & 2,770 \\
\hline 50 & Colombia & 7.55 & (3.84) & 1995 & 2,455 \\
\hline 51 & Morocco & 6.84 & (2.02) & 1999 & 2,383 \\
\hline 52 & Tunisia & 6.32 & $(0.72)$ & 1999 & 4,758 \\
\hline 53 & Indonesia & 4.83 & (1.81) & 1999 & 5,538 \\
\hline 54 & Kuwait & 2.49 & (1.59) & 1995 & 1,442 \\
\hline
\end{tabular}

Notes: Coefficient estimate on books at home. - Dependent variable: TIMSS-95/TIMSS-Repeat international test score (mean of math and science). - Regressions control for: student age, student gender, family status, student born in country, mother born in country, father born in country, interactions between the three immigration variables and books, a TIMSS-Repeat dummy and a constant. - Regressions weighted by students' sampling probabilities. Clustering-robust standard errors (taking account of correlated error terms within schools) in parentheses. $-{ }^{\mathrm{a}}$ Japan also participated in 1995, but the question on books at home was not administered at an internationally comparable scale. - OECD member states marked in bold. - All estimates are statistically significantly different from zero at the 1 percent level, with the exceptions of Colombia (5 percent level) and Kuwait (14 percent level). 
Table 4: Numerical Examples of the Predicted Family-Background Effect

\begin{tabular}{|c|c|c|c|c|c|c|c|}
\hline & & $E=15 \%$ & $E=30 \%$ & $E=45 \%$ & $E=60 \%$ & $E=75 \%$ & $E=90 \%$ \\
\hline \multirow[t]{5}{*}{$C=4$} & $K=1.25$ & $6.55(6.10)$ & 7.99 & 7.82 & $8.48(7.65)$ & $8.31(7.48)$ & $6.17(5.34)$ \\
\hline & $K=1.5$ & $6.55(6.10)$ & 7.93 & 7.75 & $8.46(7.56)$ & $8.28(7.38)$ & $6.10(5.20)$ \\
\hline & $K=1.75$ & $6.55(6.10)$ & 7.84 & 7.65 & $8.42(7.45)$ & 8.22 (7.25) & $6.02(5.05)$ \\
\hline & $K=2.0$ & $6.55(6.10)$ & 7.73 & 7.52 & $8.36(7.31)$ & 8.15 (7.10) & 5.95 (4.90) \\
\hline & $K=2.25$ & $6.55(6.10)$ & 7.60 & 7.37 & 8.27 (7.15) & 8.05 (6.92) & 5.87 (4.75) \\
\hline \multirow[t]{5}{*}{$C=6$} & $K=1.25$ & 5.10 & 6.99 & 6.82 & $6.73(6.65)$ & $6.56(6.48)$ & 4.42 (4.35) \\
\hline & $K=1.5$ & 5.10 & 6.93 & 6.75 & $6.71(6.56)$ & 6.53 (6.38) & 4.35 (4.20) \\
\hline & $K=1.75$ & 5.10 & 6.84 & 6.65 & $6.67(6.45)$ & $6.47(6.25)$ & 4.27 (4.05) \\
\hline & $K=2.0$ & 5.10 & 6.73 & 6.52 & $6.61(6.31)$ & $6.49(6.10)$ & $4.20(3.90)$ \\
\hline & $K=2.25$ & 5.10 & 6.60 & 6.37 & $6.52(6.15)$ & $6.30(5.92)$ & $4.12(3.75)$ \\
\hline \multirow[t]{5}{*}{$C=8$} & $K=1.25$ & 4.10 & 5.99 & 5.82 & 5.65 & 5.48 & 3.35 \\
\hline & $K=1.5$ & 4.10 & 5.93 & 5.75 & 5.56 & 5.38 & 3.20 \\
\hline & $K=1.75$ & 4.10 & 5.84 & 5.65 & 5.45 & 5.25 & 3.05 \\
\hline & $K=2.0$ & 4.10 & 5.73 & 5.52 & 5.30 & 5.10 & 2.90 \\
\hline & $K=2.25$ & 4.10 & 5.60 & 5.37 & 5.15 & 4.92 & 2.75 \\
\hline
\end{tabular}

Notes: Family-background effect $\mathrm{FBE}=\operatorname{FBE}(K, E, C)$, where $K=$ pre-school duration, $E=$ pre-school enrollment and $C=$ number of comprehensive school years. $t=0.5, \Delta T=6(0), S=9, \delta_{l}=3 / 4, \delta_{h}=5 / 4, \alpha=2, \beta=1 / 2, \gamma=1$, $k=6, f_{0}=1, f_{1}=2$. 
Table 5: Education Policy and Inequality of Opportunity: Country-Level Specification

\begin{tabular}{lcc}
\hline \hline & $(1)$ & $(2)$ \\
\hline Age of first tracking & $-1.225^{* * *}$ & $-0.926^{* * *}$ \\
Pre-school enrollment & $(0.337)$ & $(0.339)$ \\
& $0.369^{* * *}$ & $0.213^{*}$ \\
Pre-school enrollment squared & $(0.090)$ & $(0.115)$ \\
& $-0.003^{* * *}$ & $-0.002^{*}$ \\
Pre-school duration & $(0.001)$ & $(0.001)$ \\
& $-1.377^{*}$ & -1.317 \\
Educational expenditure per student $/ 1000$ & $(0.781)$ & $(0.867)$ \\
& & -0.140 \\
GNI per capita /1000 & & $(0.411)$ \\
& & -0.158 \\
Country mean test score /100 & & $(0.219)$ \\
& & $4.916^{* * *}$ \\
Observations (countries) & 53 & $(1.714)$ \\
$R^{2}$ (adjusted) & 0.400 & 49 \\
\hline \hline
\end{tabular}

Notes: Dependent variable: estimated family-background effect (FBE) of Table 3. - Regressions apply the Anderson (1993) weighted estimation procedure to account for estimated dependent variable. - Standard errors in parentheses.

Significance level: ${ }^{* * *} 1$ percent. $-{ }^{*} 10$ percent. 
Table 6: Education Policy and Inequality of Opportunity: Student-Level Interaction Specification with Main Systemic Effects

\begin{tabular}{lcc}
\hline \hline & $(3)$ & $(4)$ \\
\hline Books & $75.530^{* * *}$ & $82.139^{* * *}$ \\
Age of first tracking * books & $(13.791)^{* * *}$ & $(10.660)^{* *}$ \\
& $-2.896^{* *}$ & $-2.624^{* * *}$ \\
Pre-school enrollment * books & $(0.882)^{* *}$ & $(0.701)^{* *}$ \\
& $0.579^{* *}$ & $0.546^{* *}$ \\
Pre-school enrollment squared * books & $(0.244)^{* * *}$ & $(0.232)^{* *}$ \\
& $-0.006^{* *}$ & $-0.005^{* *}$ \\
Pre-school duration * books & $(0.002)^{* * * *}$ & $(0.002)$ \\
& $-6.875^{* * *}$ & $-8.141^{* * *}$ \\
Educational expenditure per student /1000* books & $(1.977)$ & $(1.988)$ \\
& & 0.277 \\
GNI per capita /1000 * books & & $(0.702)$ \\
& & $-0.778^{*}$ \\
Age of first tracking & & $(0.450)$ \\
Pre-school enrollment & 5.843 & 3.712 \\
& $(5.875)$ & $(4.937)$ \\
Pre-school enrollment squared & -0.105 & -0.490 \\
& $(1.025)$ & $(0.867)$ \\
Pre-school duration & 0.009 & 0.007 \\
& $(0.010)$ & $(0.008)$ \\
Educational expenditure per student /1000 & $25.747^{* *}$ & $34.222^{* * *}$ \\
& $(11.887)$ & $(11.518)$ \\
GNI per capita /1000 & & -2.372 \\
& & $(4.045)$ \\
Observations (students) & & $5.331^{*}$ \\
Primary sampling units (countries) & & $(2.702)$ \\
\hline$R^{2}$ & & 276,577 \\
& & 50 \\
Nos: Den & & 0.243 \\
\hline
\end{tabular}

Notes: Dependent variable: TIMSS-95/TIMSS-Repeat international test score (mean of math and science). - All regressions control for student age, student gender, family status, student born in country, mother born in country, father born in country, interactions between the three immigration variables and books, a TIMSS-Repeat dummy and a constant. - Regressions weighted by students' sampling probabilities. Clustering-robust standard errors (taking account of correlated error terms within countries) in parentheses.

Significance level (based on clustering-robust standard errors): ${ }^{* * *} 1$ percent. - ${ }^{* *} 5$ percent. $-{ }^{*} 10$ percent. 
Table 7: Education Policy and Inequality of Opportunity: Student-Level Interaction Specification with Country Fixed Effects, Full Sample

\begin{tabular}{lccc}
\hline \hline & $(5)$ & $(6)$ & $(7)$ \\
\hline Books & $29.368^{* * *}$ & 10.612 & $30.612^{* *}$ \\
Age of first tracking * books & $(5.316)$ & $(8.534)$ & $(11.973)$ \\
& $-1.074^{* * *}$ & $-0.893^{* * *}$ & $-0.968^{* * *}$ \\
Pre-school enrollment * books & $(0.284)$ & $(0.277)$ & $(0.341)$ \\
& $0.336^{* * *}$ & $0.262^{* * *}$ & 0.041 \\
Pre-school enrollment squared * books & $(0.085)$ & $(0.081)$ & $(0.100)$ \\
& $-0.003^{* * *}$ & $-0.002^{* * *}$ & -0.000 \\
Pre-school duration * books & $(0.001)$ & $(0.001)$ & $(0.001)$ \\
& $-1.303^{*}$ & $-1.545^{* *}$ & $-2.103^{* *}$ \\
Educational expenditure per student /1000* books & $(0.717)$ & $(0.689)$ & $(1.018)$ \\
& & -0.136 & -0.178 \\
GNI per capita /1000 * books & & $(0.396)$ & $(0.395)$ \\
Country mean test score /100 * books & & -0.144 & 0.161 \\
Private expenditure share * books & & $(0.225)$ & $(0.224)$ \\
Private enrollment share * books & & $4.337^{* *}$ & 1.016 \\
& & $(1.753)$ & $(1.654)$ \\
Observations (students) & & & 0.158 \\
Primary sampling units (countries) & & & $(0.060)$ \\
$R^{2}$ & & & $-0.099^{* * *}$ \\
\hline \hline
\end{tabular}

Notes: Dependent variable: TIMSS-95/TIMSS-Repeat international test score (mean of math and science). - All regressions control for: country fixed effects, student age, student gender, family status, student born in country, mother born in country, father born in country, interactions between the three immigration variables and books, interactions between all these previous variables and country dummies and a constant. - Regressions weighted by students' sampling probabilities. - Clustering-robust standard errors (taking account of correlated error terms within countries) in parentheses.

Significance level (based on clustering-robust standard errors): ${ }^{* * *} 1$ percent. $-{ }^{* *} 5$ percent. $-{ }^{*} 10$ percent. 
Table 8: Education Policy and Inequality of Opportunity: Student-Level Interaction Specification with Country Fixed Effects, OECD Sample

\begin{tabular}{lcrc}
\hline \hline & $(8)$ & $(9)$ & $(10)$ \\
\hline Books & $29.003^{* * *}$ & 9.083 & $39.075^{* *}$ \\
Age of first tracking * books & $(8.731)$ & $(18.848)$ & $(16.727)$ \\
& $-0.844^{* *}$ & -0.488 & $-0.970^{* *}$ \\
Pre-school enrollment * books & $(0.390)$ & $(0.421)$ & $(0.400)$ \\
& $0.329^{* * *}$ & $0.333^{* *}$ & 0.125 \\
Pre-school enrollment squared * books & $(0.110)$ & $(0.132)$ & $(0.138)$ \\
& $-0.003^{* * *}$ & $-0.003^{* *}$ & -0.001 \\
Pre-school duration * books & $(0.001)$ & $(0.001)$ & $(0.001)$ \\
& $-2.280^{* *}$ & -1.542 & $-2.231^{* *}$ \\
Educational expenditure per student /1000* books & $(0.967)$ & $(0.966)$ & $(1.038)$ \\
GNI per capita /1000 * books & & -0.477 & -0.155 \\
Country mean test score /100 * books & & $(0.437)$ & $(0.440)$ \\
& & 0.032 & 0.071 \\
Private expenditure share * books & & $(0.307)$ & $(0.283)$ \\
Private enrollment share * books & & -2.742 & -0.819 \\
& & $(2.893)$ & $(2.844)$ \\
\hline Observations (students) & & & $0.169^{* *}$ \\
Primary sampling units (countries) & & & $(0.068)$ \\
$R^{2}$ & & & $-0.081^{* *}$ \\
\hline \hline
\end{tabular}

Notes: Dependent variable: TIMSS-95/TIMSS-Repeat international test score (mean of math and science). - All regressions control for: country fixed effects, student age, student gender, family status, student born in country, mother born in country, father born in country, interactions between the three immigration variables and books, interactions between all these previous variables and country dummies and a constant. - Regressions weighted by students' sampling probabilities. - Clustering-robust standard errors (taking account of correlated error terms within countries) in parentheses.

Significance level (based on clustering-robust standard errors): ${ }^{* * *} 1$ percent. $-{ }^{* *} 5$ percent. 
Figure 1: Family Background and Human Capital Accumulation

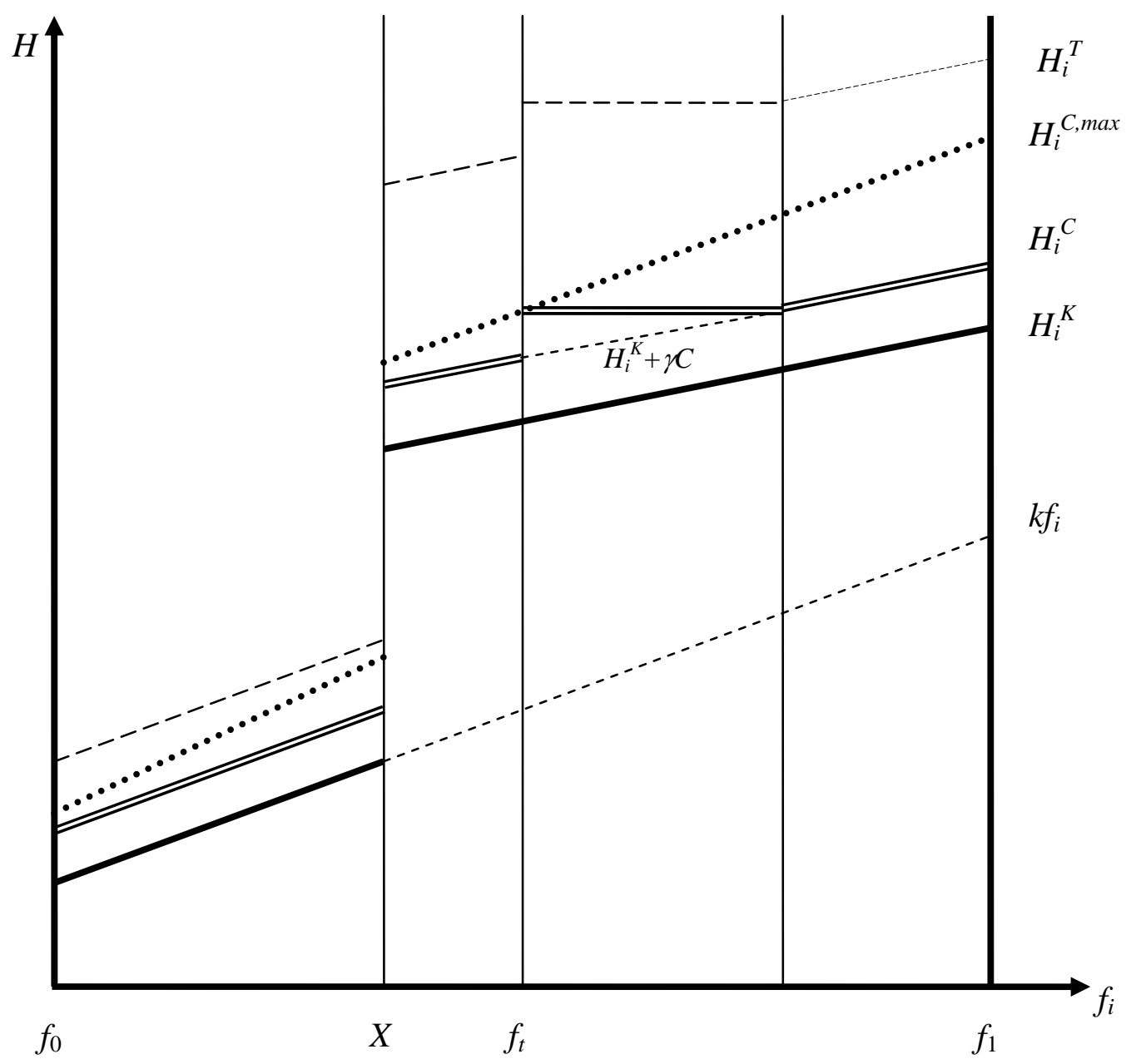


Figure 2: Pre-School Enrollment and the Family-Background Effect: Theory

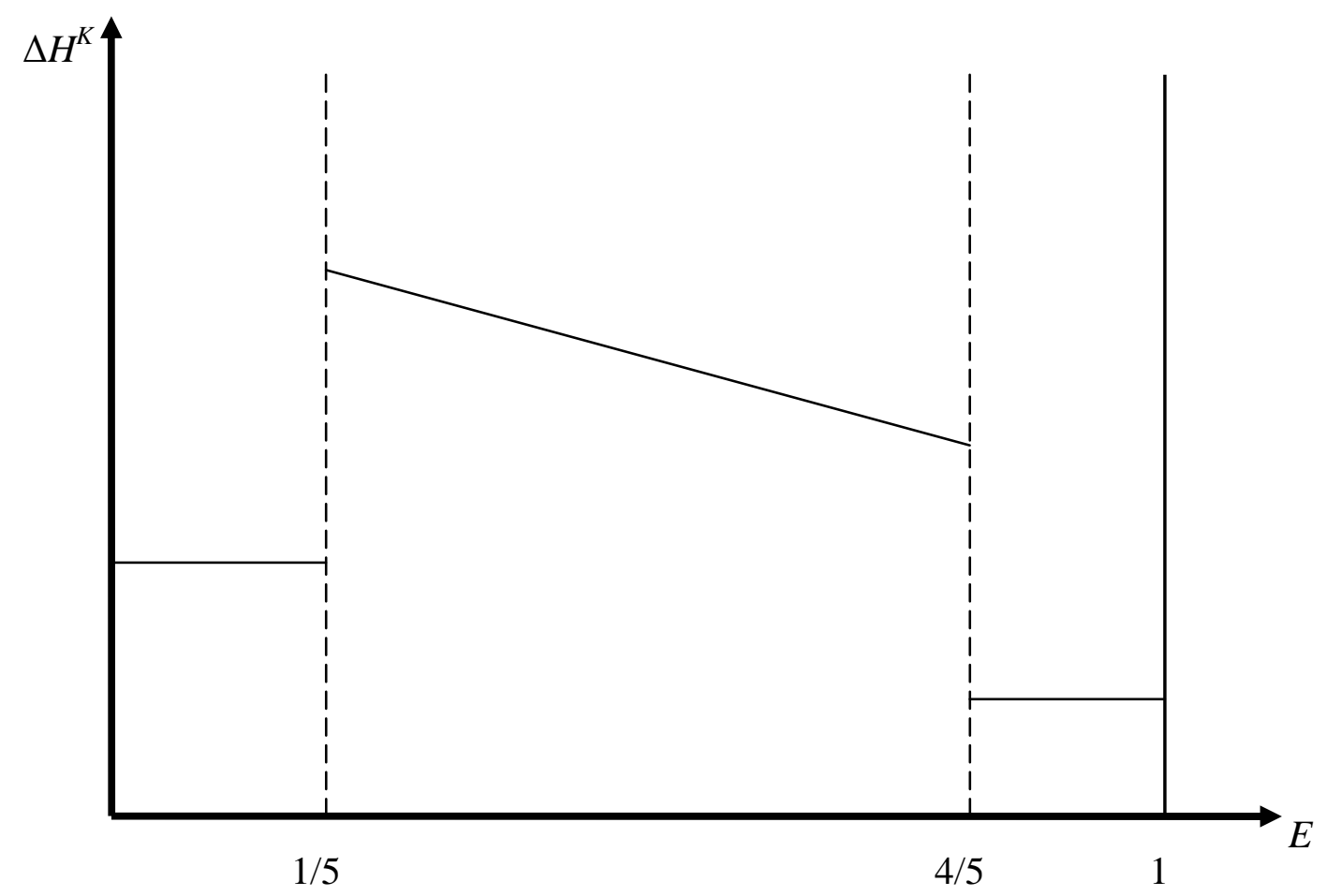


Figure 3: Pre-School Enrollment and the Family-Background Effect: Evidence

Family-background effect

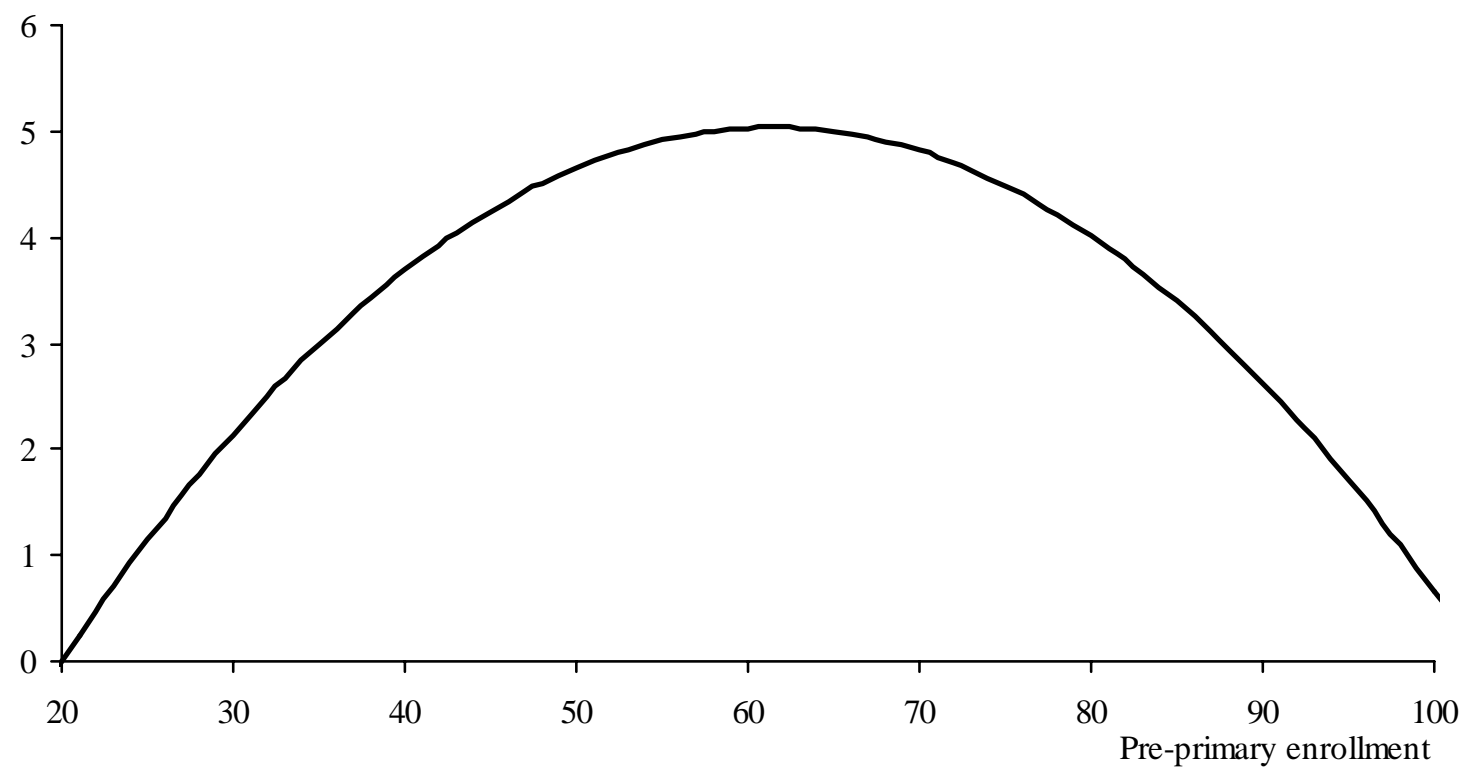

Note: Estimated interaction effect of books at home with pre-school enrollment and its square in the student-level interaction specification with country fixed effects reported in column (5) of Table 7. 